\title{
Synaptic Interactions between GABA-immunoreactive Profiles and the Terminals of Functionally Defined Myelinated Nociceptors in the Monkey and Cat Spinal Cord
}

\author{
Francisco J. Alvarez, Anahid M. Kavookjian, and Alan R. Light \\ Department of Physiology, School of Medicine, University of North Carolina, Chapel Hill, North Carolina'27599
}

This study analyzes the synaptic interactions between the central terminals of $\mathrm{A} \delta$ high threshold mechanoreceptors (A $\delta$ HTMs) and GABA-immunoreactive profiles. A $\delta$ HTM primary afferents from three monkeys and one cat were electrophysiologically identified and intracellularly labeled with HRP, and their terminal arborizations in laminae I and II of the sacrocaudal spinal cord were studied at the ultrastructural level. GABA-immunoreactive profiles in relation to A $\delta$ HTM terminals were demonstrated using postembedding colloidal gold techniques.

Monkey A $\delta$ HTM terminals $(n=131)$ usually constituted the central element of synaptic glomeruli; they established large asymmetric synaptic contacts with 1-13 dendrites (modal value 2-4) and were surrounded by 0-6 peripheral axon terminals (modal value 2-3). The large majority (around $85 \%$ ) of the peripheral axon terminals were GABA immu-

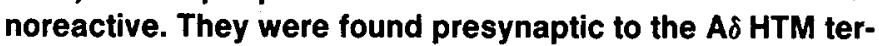
minal and/or to dendrites postsynaptic to the primary afferent terminal. Furthermore, all peripheral axon terminals found presynaptic to the A $\delta$ HTM terminals showed GABA immunoreactivity. Wilthin a single $A \delta \mathrm{HTM}$ fiber, this synaptic arrangement was found in $20-60 \%$ of its boutons. In addition, $28 \%$ of the postsynaptic dendritic profiles displayed weak GABA immunoreactivity. Some of them contained vesicles; however, only in a few cases did we observe synapses between a GABA-immunoreactive vesicle-containing dendrite and a dendritic profile postsynaptic to an A $\delta$ HTM terminal. Similar synaptology and interactions with GABA-immunoreactive profiles were displayed by the terminals of the single cat A $\delta$ HTM fiber studied.

Our data support the hypothesis that GABA-containing neurons use both presynaptic and/or postsynaptic mechanisms to exert a powerful control, presumably inhibitory, over the transmission of nociceptive information between A $\delta$ HTM afferents and second-order neurons in monkey and cat spi-

\footnotetext{
Received Dec. 23, 1991; revised Feb. 28, 1992; accepted Mar. 4, 1992.

We thank Mr. Scott Donaghy, Ms. Helen Willcockson, and Ms. Bonnie Blake for their technical assistance. We also thank Drs. P. Petrusz, A. Rustioni, and S. DiBiasi, who kindly provided the GARA antibody and helped in developing the immunocytochemical techniques used in this report. This work was supported by U.S. Public Health Service Grants DA04420 and NS16433. Electron microscopy facilities were partly supported by U.S. Public Health Service Grant NS14899. F.J.A. is a postdoctoral research associate supported by a grant from the Consejo Superior de Investigaciones Cientificas (Spain).

Correspondence should be addressed to Dr. Alan R. Light, Department of Physiology, 79 Medical Sciences Research Building, CB\#7545, University of North Carolina, College of Medicine, Chapel Hill, NC 27599.

Copyright (C) 1992 Society for Neuroscience 0270-6474/92/122901-17\$05.00/0
}

nal cord. Our results also imply that GABA may be released within the synaptic glomeruli formed by A $\delta$ HTM terminals either by local dendrites or by axon terminals. We discuss the possibility that these GABAergic synapses can be driven by inputs from both primary afferents and/or descending systems to modulate the transmission of nociceptive sensory information.

Myelinated nociceptive fibers constitute a major class of primary afferent fiber conveying nociceptive information from the periphery to the spinal cord (Perl, 1984). These fibers are most responsive to cutaneous mechanical stimulation, have thresholds in the noxious range, and display a broad range of conduction velocities ( 5 to over $40 \mathrm{~m} / \mathrm{sec}$ ) with a mean that falls in the A $\delta$ domain; thus, they are usually referred to as $\mathrm{A} \delta$ highthreshold mechanoreceptors (HTMs). This type of nociceptive primary afferent has been amenable to light and electron microscopic studies because it could be injected with HRP through the recording micropipettes after electrophysiological characterization (Light and Perl, 1979; Réthelyi et al., 1982). In these studies, A $\delta$ HTM fibers were seen projecting predominantly to lamina I (LI) and lamina II (LII) of the monkey and cat spinal cords (Light and Perl, 1979), where they established synaptic contacts with various types of dendritic profiles and received presynaptic input from vesicle-containing profiles that were tentatively classified as axon terminals (Réthelyi et al., 1982). However, the nature of the profiles post- and presynaptic to A $\delta$ HTM boutons remained largely unknown.

Recently, major improvements in immunocytochemical postembedding techniques (De Zeeuw et al,, 1988; Phend et al., 1992) and the development of very sensitive antibodies (Hepler et al., 1986) have allowed us to reexamine the issue of which neurotransmitter is contained inside the neural profiles pre- and postsynaptic to the A $\delta$ HTM fibers our group studied 10 years ago. Several lines of evidence point toward GABA as one of the possible neurotransmitters. First, a major plexus of GABAergic fibers has been shown in LI and LII of the rat (McLaughlin et al., 1975) and monkey spinal cord (Carlton and Hayes, 1990). Second, GABAergic terminals have been described in relation to small-caliber primary afferent terminals undergoing degeneration after dorsal root rhizotomy (Barber et al., 1978). Third, there is considerable physiological evidence implicating GABA in the depolarization of large-diameter primary afferents, which is thought to be mediated by a presynaptic mechanism (for revicw, sce Levy, 1977; Nicoll and Alger, 1979). Accordingly, GABA-immunoreactive terminals were found presynaptic to Ia boutons in the cat spinal cord (Maxwell et al., 1990). In addition, 
Table 1. Characteristics of the primary afferent fibers studied

\begin{tabular}{llll} 
Code $^{a}$ & Receptor type $^{b}$ & $\begin{array}{l}\text { CV } \\
(\mathrm{m} / \mathrm{sec})^{c}\end{array}$ & $\begin{array}{l}\text { HRP } \\
\text { labeling }\end{array}$ \\
\hline HDM28\#1 $^{d}$ & HTM, monkey & 27.7 & Light \\
HDM30\#4 & HTM, monkey & 50.0 & Dense \\
PP5\#3 & HTM, monkey & 16.2 & Very dense \\
HD96\#5 $5^{d}$ & HTM, cat & 36.0 & Dense
\end{tabular}

adentification code for individual animal and unit.

${ }^{b}$ Receptor type classification according to Perl (1984).

c Conduction velocity, measured in the dorsal root of the primary afferent.

${ }^{d}$ The physiology and ultrastructural characteristics of these fibers have been previously reported (Réthelyi et al., 1982).

unidentified terminals that had morphological characteristics of fine-caliber primary afferent terminals were recently shown to receive synaptic input from GABAergic profiles in LII of the rat spinal cord (Todd and Lochhead, 1990) and the cat trigeminal subnucleus caudalis (Basbaum et al., 1986). However, other possibilities could also exist since cholinergic and glycinergic axon terminals have been shown to be presynaptic to primary afferent glomerular terminals (Ribeiro-da-Silva and Cuello, 1990; Todd, 1990) and considerable physiological and pharmacological evidence has been accumulated for enkephalinergic, serotoninergic, catecholaminergic, and purinergic presynaptic actions over small-diameter primary afferents (for recent comprehensive reviews, see Yaksh, 1986; Evans, 1989; Sawynok and Sweeney, 1989).

Therefore, we have used a postembedding colloidal gold technique and GABA antibodics to characterize neurochemically the presynaptic input to identified A $\delta$ HTM fibers. In addition, we studied all other GABAergic synaptic interactions that occur within the glomerular structures formed by the central terminals of A $\delta$ HTM fibers. Four A $\delta$ HTM fibers from three different monkeys and one cat were included in this study. Their main electrophysiological characteristics are summarized in Table 1.

An ultrastructural description of the morphology of three of the A $\delta$ HTM fibers appeared in a previous report (Réthelyi et al., 1982). Since in the previous study the major emphasis was on cat A $\delta$ HTMs, we describe here in some detail the ultrastructural morphology of monkey A $\delta$ HTM synaptic boutons. Preliminary results of this work have been presented in abstract form (Alvarez et al., 1991a).

\section{Materials and Methods}

The experimental material used in this study was prepared several years ago with the particular aim of analyzing the ultrastructural morphology of cat and monkey fine myelinated primary afferent terminals (Réthelyi et al., 1982). Briefly, recordings were made with fine microelectrodes filled with a solution of horseradish peroxidase (HRP) from single primary afferent fibers at the dorsal root entry zone of the spinal cord sacrocaudal segments of adult domestic cats and rhesus monkeys. After characterizing a unit as a myelinated nociceptor, HRP was injected by iontophoresis. Details of the experimental procedures, electrodes, and electrometer techniques were described elsewhere (Light and Perl, 1979; Jochem et al., 1981). After $1-9 \mathrm{hr}$, the animals were perfused through the carotid artery with a brief rinse of phosphate-buffered saline (PBS; $0.1 \mathrm{M}, \mathrm{pH} 7.4$ ) followed by a fixative consisting of $2 \%$ glutaraldehyde, $2 \%$ paraformaldehyde, and $4 \%$ sucrose in phosphate buffer $(0.1 \mathrm{M}, \mathrm{pH}$ 7.4). The spinal cord was removed and postfixed in the same fixative overnight. The next day, $50 \mu \mathrm{m}$ serial sections were cut in the parasagittal plane, reacted with diaminobenzidine (DAB) and $\mathrm{H}_{2} \mathrm{O}_{2}$, osmicated with a $2 \%$ solution of $\mathrm{OsO}_{4}$, dehydrated in alcohols, and flat-embedded in an Epon-Araldite mixture. Detailed descriptions of the histological tech niques can be found in Réthelyi et al. (1982) and Metz et al. (1982).

Light microscopy photomicrographs and camera lucida drawings were made from those areas of the thick plastic sections that contained HRP. labeled primary afferent terminals. The photographed area was cut from the thick section and glued to an electron microscope capsule. Ribbons of 30-60 ultrathin sections were followed by a $1 \mu \mathrm{m}$ semithin section. The ribbon was then broken in order to mount three to six serial sections on each formvar-coated, single-slot, nickel grid. Consecutive grids were used for the following procedures: immunostaining with GABA antiserum, control with preimmune antiserum, control with non-GABA antisera [usually substance $\mathbf{P}$ (SP) or calcitonin gene-related peptide (CGRP) antisera], and preabsorption control. After the immunoprocess some ultrathin sections were scanned before they were counterstained to allow for better identification of weakly HRP-labeled primary afferent terminals. The ultrathin sections were then counterstained with $2 \%$ uranyl acetate in $50 \%$ ethanol followed by Reynold's lead citrate. Semithin sections were stained with $1 \%$ toluidine and used for orientation purposes and recording the location of the HRP-filled terminals studied.

Immunostaining protocols. The grids were immunostained according to the protocol used by De Zeeuw et al. (1988). The grids were rinsed twice for 5-10 min in droplets of $0.05 \mathrm{M}$ Tris buffer ( $\mathrm{pH}$ 7.4) containing $0.9 \% \mathrm{NaCl}$ and $0.1 \%$ Triton X-100 (TBS-TX) and left overnight at room temperature in a droplet of rabbit anti-GABA antisera diluted 1:1000-1:5000 in TBS-TX. The grids were then rinsed in TBS-TX twice for $5 \mathrm{~min}$, stored in the same solution for $20-25 \mathrm{~min}$, rinsed for $10 \mathrm{~min}$ in TBS-TX ( $\mathrm{pH} 8.2$ ), incubated for $2-3 \mathrm{hr}$ in goat anti-rabbit IgG labeled with colloidal gold particles of $10 \mathrm{~nm}$ (EMGARG10, Janssen), and diluted $1: 25$ in TBS-TX (pH 8.2). Finally, the grids were rinsed twice for $5 \mathrm{~min}$ in a TBS-TX droplet. Buffer and salts were remove by dipping the grids in double-distilled water several times.

Antibody and method specificity. An anti-GABA polyclonal antiserum (ref. A-GABA/HC 483a) raised in rabbit was used in this study. This antiserum was kindly donated by Dr. P. Petrusz (Department of Cell Biology and Anatomy, University of North Carolina), and information concerning its production and specificity has been published elsewhere in abstract form (Hepler et al., 1986). In our material, specificity of the immunolabeling was assessed by preabsorption experiments in which the GABA antiserum diluted for tissue reaction was preincubated with $1 \mu \mathrm{M}$ GABA (Sigma) for $24 \mathrm{hr}$. In serial sections, GABA-immunoreactive profiles did not label with the preabsorbed GABA antisera or with antisera against SP (Dr. P. Petrusz; dilution, 1:10,000) or CGRP (Península Lab.; dilution, 1:4000) or normal preimmune rabbit antisera.

Analysis and quantitation of GABA immunoreactivity. Immunostained sections were analyzed with a Zeiss $10 \mathrm{EM}$ electron microscope. In our material, GABA immunolabeling was characterized by an accumulation of gold particles over certain profiles against a generalized background labeling. Some profilcs peripheral to the A $\delta$ HTM terminal (e.g., dendrites) were very weakly labeled, and therefore we devised a method for identifying labeled profiles against the background. This consisted of constructing labeling density plots as shown in Figure 8. In these plots the gold density inside structures peripheral to A $\delta$ HTM terminals was compared with the gold density in the HTM terminal and in other random structures of the adjacent neuropil and with background gold density. In order to avoid artifacts that may occur in single sections, we estimated gold densities inside each peripheral profile by pooling together data from two to seven serial sections. Several methods were used for estimating background levels. In our hands, the more reasonable and bias-free values were obtained by counting all the gold particles present in a sample of photographs (magnification, $\sim 35,000 \times$ ) containing profiles included in the quantitation. We then subtracted those gold particles contained in heavily labeled structures and calculated the overall background gold density in the photograph. Different density plots were obtained for different immunocytochemical runs.

Statistical analysis was run on PCSAS (Personal Computer Statystical Analysis System); ANOVA was performed using general linear model procedure for comparing the gold density inside dendrites and terminals around the HRP profiles and our background estimates. Further statistics were only run when ANOVA was statistically significant. Duncan's multiple range test was used to compare individual groups. $t$ test analysis was used to compare gold densities between terminals immunostained with preabsorbed and nonpreabsorbed antibodies and background. $t$ test analysis was also used to compare background estimates with two individual dendrites displaying a gold density around two times background, measured in six and seven serial sections, respectively. We 
Table 2. Numbers, types, immunoreactivity, and synaptology of profiles peripheral to myelinated HTM primary afferent synaptic boutons

\begin{tabular}{|c|c|c|c|c|c|c|c|c|c|}
\hline \multirow[b]{2}{*}{ Fiber } & \multirow{2}{*}{$\begin{array}{l}\text { Boutons } \\
\text { serially } \\
\text { recon- } \\
\text { structed } \\
(n) \\
\end{array}$} & $\begin{array}{l}\text { Postsyn } \\
\text { dendrit }\end{array}$ & $\begin{array}{l}\text { ptic } \\
(n)\end{array}$ & \multirow{2}{*}{$\begin{array}{l}\text { Boutons } \\
\text { making } \\
\text { onc } \\
\text { synapse } \\
(n)\end{array}$} & \multirow{2}{*}{$\begin{array}{l}\text { Postsynaptic } \\
\text { dendrites with } \\
\text { vesicles (\%) }\end{array}$} & \multicolumn{2}{|c|}{ Axon terminals $(n)$} & \multirow{2}{*}{$\begin{array}{l}\text { Axon } \\
\text { terminals } \\
\text { that are } \\
\text { GABA } \\
\text { immuno- } \\
\text { reactive }(\%)^{a}\end{array}$} & \multirow{2}{*}{$\begin{array}{l}\text { HTM } \\
\text { terminals } \\
\text { postsynaptic } \\
\text { to GABA } \\
\text { immunoreactive } \\
\text { terminals }(n)^{b}\end{array}$} \\
\hline & & Range & Mean \pm SD & & & Range & Mean \pm SD & & \\
\hline HDM $28 \# 1$ & 12 & $1-11$ & $4.25 \pm 2.71$ & 1 & $47 \% \quad(51)$ & $0-4$ & $2.00 \pm 1.08$ & $87.5 \%(26)$ & $5(8)$ \\
\hline PP5\#3 & 22 & $1-13$ & $3.73 \pm 2.65$ & 4 & $35.4 \%(82)$ & $0-6$ & $2.64 \pm 1.4$ & $84 \% \quad(44)$ & $4(7)$ \\
\hline
\end{tabular}

Numbers in parentheses indicate the total number of profiles analyzed.

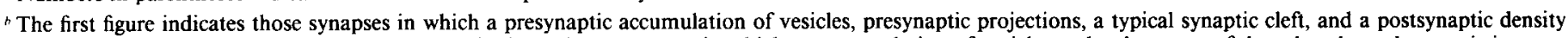

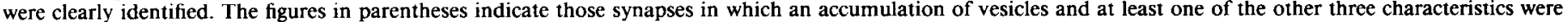
present.

considered statistically significant probabilities to be $p<0.05$. Our statistical analysis indicated that structures displaying gold density above two times the mean background level were significantly different $(p<$ 0.05 ) from background; these were considered weakly labeled. We considered structures to be heavily labeled when they contained above four times the mean background level. Similar criteria have been used in other postembedding colloidal gold studies of amino acid neurotransmitters in the spinal cord (Todd and Lochhead, 1990; Merighi et al., 1991).

In order to appreciate the full extent of the synaptic interactions that occurred within glomerular terminals established by A $\delta$ HTM terminals, 22 of the 65 boutons sampled from fiber PP5 $\# 3$ and 12 of the 56 boutons sampled from fiber HDM28\#1 were randomly selected and completely reconstructed from 15-45 serial section photographs at a final magnification of $35,000 \times$. We then counted the number, type, synaptic interactions, and GABA immunoreactivity of all the peripheral profiles surrounding the HRP-filled terminals (Table 2). Six terminals from fiber HD96\#5 were partially reconstructed for comparison.

\section{Results}

Monkey A $\delta$ HTM fibers

$L M$ morphology

The light microscopy morphology, course, and arborization patterns of the A $\delta$ HTM fibers studied here were identical to those reported in the original descriptions (Light and Perl, 1979). Briefly, the parent axons gave off several collaterals that entered the dorsal horn gray matter and arborized in numerous higherorder branches largely oriented in the longitudinal axis (Fig. 1). Rows of "en passant" varicosities or enlargements of various sizes and shapes decorated all collaterals. Although collaterals from each of the three monkey A $\delta$ HTM fibers could be found bearing varicosities in all three laminae studied (1, Il, and III), they were usually concentrated in $\mathrm{LI}$ and outer LII ( $\left.\mathrm{LII}_{o}\right)$. Most varicosities were $1-3 \mu \mathrm{m}$ in diameter $(1.79 \pm 0.49 ; n-100)$ and $1-5 \mu \mathrm{m}$ in length $(3.08 \pm 1.00 ; n=100)$. In addition, some fiber swellings were $5-12 \mu \mathrm{m}$ in length and about the same diameter as a typical varicosity. We refer to these structures as fiber enlargements (e.g., Fig. 2E). Frequently, varicosities and enlargements displayed small protrusions that were hardly resolved with light microscopy but were clearly identified later under electron microscopic examination (e.g., Fig. 6).

\section{Ultrastructural morphology}

Fine collaterals observed at the light microcopic level were usually found to be unmyelinated fiber segments stemming from very small-caliber myelinated fibers (the axon was usually $0.3-$ $0.5 \mu \mathrm{m}$ in cross section). Varicosities and enlargements on these collaterals constituted the sites where synaptic interactions occurred with the surrounding neuropil (Fig. 2). Fifty-six synaptic boutons from HDM28\#1, 65 from PP5\#3, and 10 from HDM 30\#4 were studied through serial sections. The large majority $(>85 \%)$ of these boutons displayed the typical features usually associated with spinal cord glomeruli. Thus, they were central to a variable number of peripheral neural profiles that interacted synaptically with the afferent terminal (Figs. 3-6). The entire structure was usually surrounded by glial processes. A $\delta$ HTM terminals contained many clear round synaptic vesicles and only very rarely large dense-core vesicles. Clear synaptic vesicles varied in size (40-95 $\mathrm{nm}$ in diameter), and usually they were slightly larger than those displayed by profiles peripheral to the central HRP-filled A $\delta$ HTM bouton. No major differences were observed between A $\delta$ HTM terminals sampled from LI or LII.

The overall ultrastructural morphology of HDM30\#4 and HDM28\# 1 was considered identical; howcver, small variations were observed between these two fibers and PP5\#3. Some physiological differences were also noted, for example, lower conduction velocity in PP5\#3. Peripheral profiles usually abutted the primary afferent terminal membrane and in many instances were completely invaginated inside the HRP profile. Therefore, primary afferent terminals displayed a scalloped appearance in many cross sections. Small protrusions stemmed out frequently from terminals of HDM28\#1 and HDM30\#4 (e.g., Fig. 6) and more rarely from PP5\#3 (e.g., Fig. 5B). The protrusions extended into vesicle-containing profiles and sometimes received a synaptic contact. Less frequently, they were found inside dendritic profiles or glial processes.

Two major classes of profiles were apposed to A $\delta$ HTM terminals (Figs. 2-7). The largest group received synaptic input from the A $\delta$ HTM central terminal and therefore was considered dendritic in nature. They included electron-lucent profiles that in serial sections sometimes displayed typical dendritic features such as multivesicular bodies, agranular and granular cisternae, and ribosomes. Most were considered to be dendritic spines, but we also observed small and medium dendritic shafts receiving direct synaptic input from HRP-filled terminals. The A $\delta$ HTM terminals usually established large asymmetric synapses, and sometimes more than one active zone was observed over the same dendritic profile. Many dendrites contacted by A $\delta$ HTM boutons contained varying amounts of round clear vesicles and a few large dense-core vesicles. In a few cases vesiclecontaining dendrites were presynaptic to other dendrites either inside or outside the glomeruli (Fig. 7A). Dendrodendritic synapses were small and symmetric.

The second type of profiles were usually more electron dense, did not receive synaptic input from the A $\delta$ HTM terminal, and 

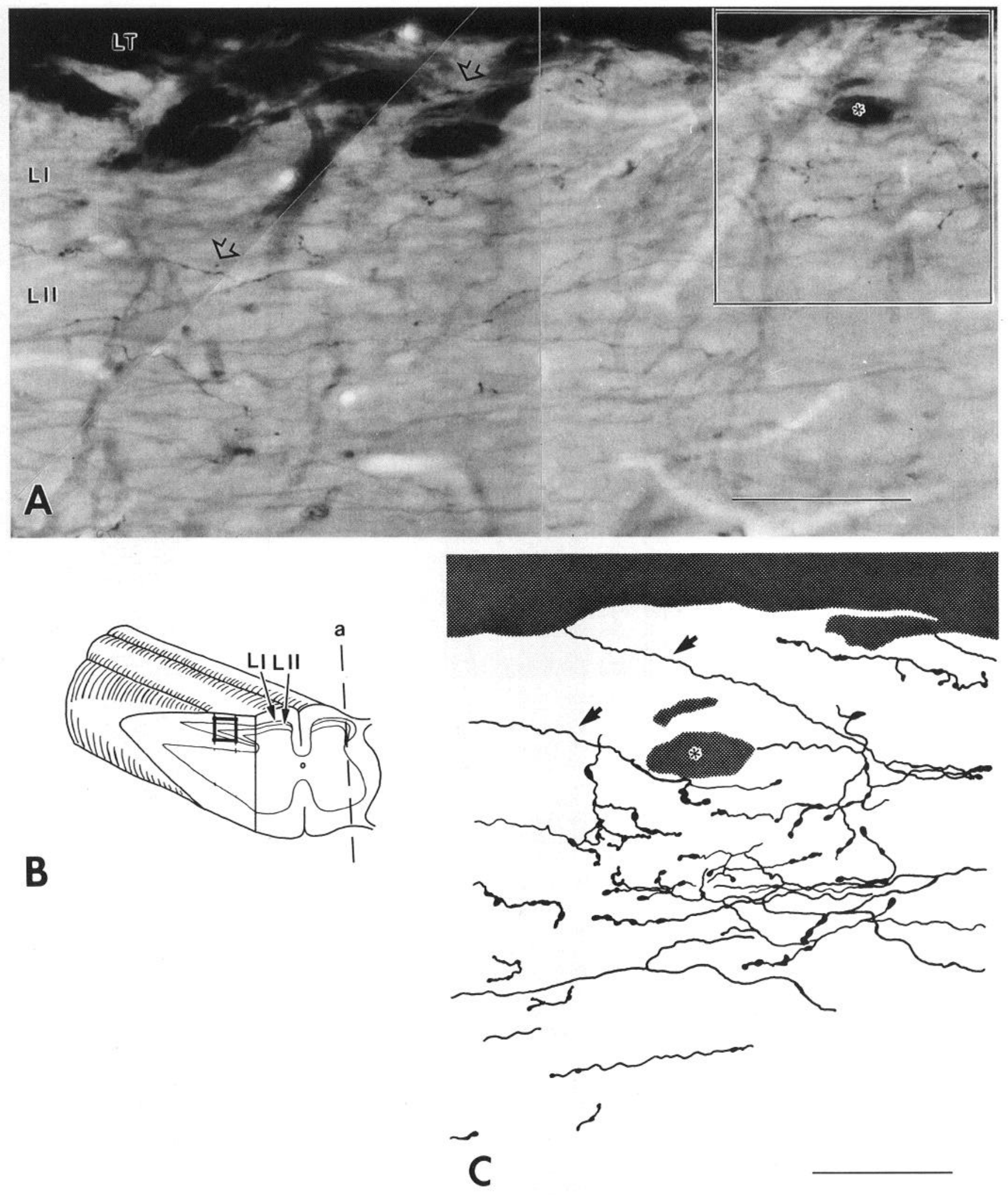

Figure 1. Light microscopy of an osmicated $50 \mu \mathrm{m}$ parasagittal section through LI and LII of the monkey spinal cord containing the terminal arborization of an HRP-filled A $\delta$ HTM fiber (PP5\#3). A is a photomontage of low-power micrographs showing part of the terminal arborization. Other segments and varicosities of the fiber lay in different focal planes and cannot be resolved in $A$. The drawing in $C$ corresponds to the boxed area in $A$. The same myelinated bundle is marked with an asterisk in both $A$ and $C$. This drawing includes all the varicosities and fiber segments found throughout the entire depth of the $50 \mu \mathrm{m}$ section. Branches of the parent axon (arrows in C) enter LI and LII from the Lissauer tract ( $L T$ ) and arborize profusely. In LI and LII, the fiber further divides and dilates at specific points forming distinct varicosities. Two open arrows in $A$ mark the positions of two fiber segments shown at the ultrastructural level in Figure 2 . The drawing in $B$ shows the general orientation of the section; $a$ indicates the plane of section. The sections were obtained parallel to the rostrocaudal axis of the spinal cord, but because the thickness of the spinal cord at the sacrolumbar level changes rapidly in the rostrocaudal direction, and because the fiber was located in the lateral curvature of LI and LII (see position of the plane of section $a$ in the right half of $B$ ), the area shown in the micrographs cuts the spinal cord in the orientation represented on the left half of $B$. Therefore, the micrograph in $A$ is a section through LI and $\mathrm{LII}_{o}$ corresponding to the boxed region in $B$. Scale bars: $A, 100 \mu \mathrm{m} ; C, 50 \mu \mathrm{m}$. 
contained large numbers of small pleomorphic clear vesicles (30-70 $\mathrm{nm}$ in diameter) and several large dense-core vesicles (80-110 nm in diameter). Frequently, these profiles could be followed through 15-20 serial sections and always displayed the characteristics of axonal fibers (Figs. 3, 4). They arose from beaded axonlike fibers that were presynaptic to several dendrites but were never postsynaptic to other structures of the neuropil. Therefore, we concluded that these profiles were most likely axon terminals; however, because of the many similarities between dendritic and axonal profiles in LI and LII (see Discussion) and the fact that we could not follow all profiles through long series of sections, we cannot completely discard the possibility that some might be dendritic in nature. Inside the $A \delta$ HTM glomeruli, axonal profiles were presynaptic both to the A $\delta$ HTM terminal and to dendrites postsynaptic to the A $\delta$ HTM terminal. Axoaxonic and axodendritic synapses established by these peripheral axonal terminals were always symmetric and very small (could only be seen through one or two serial sections) (Figs. $2 A ; 3 A, C ; 4 B ; 5 A$ ).

In some cases unlabeled terminals displaying ultrastructural and immunocytochemical (SP and/or CGRP immunoreactivity) features characteristic of primary afferents were also part of the glomerular complexes formed by A $\delta$ HTM primary afferents. In these cases both the A $\delta$ HTM and the unidentified primary afferent terminals shared dendrites and axonal profiles and established similar types of synaptic connections. In many instances both primary afferent terminals were joined by desmosomes (Fig. 5B). Synaptic connections between two primary afferents terminals were never found. Clustering of the A $\delta$ HTM terminal with other unlabeled primary afferent terminals was more common for boutons of PP5\#3 fiber.

\section{GABA immunoreactivity in profiles surrounding $A \delta H T M$ central terminals}

Most axonal profiles surrounding the HRP-labeled profiles were GABA immunoreactive. Gold particles were scattered throughout the cytoplasm of immunoreactive profiles (Figs. 3-7). High densitics were associated with small clear vesicles, and sometimes also with large dense-core vesicles. Frequently, high gold densities were also associated with mitochondria inside immunoreactive profiles but not inside nonimmunoreactive profiles. Gold densities inside 44 axonal terminals adjacent to a random sample of A $\delta$ HTM terminals were examined quanti- tatively and exceeded our background estimates by more than four times in $88 \%$ of the cases and by more than two times in $97 \%$ of the cases (Fig. 8). Axonal profiles with large numbers of synaptic vesicles were highly immunoreactive (gold densities 7 10 times background levels). High gold densities inside axonal terminals fell to background levels or below when the primary antibody was preabsorbed with GABA (Figs. $3 B, 6 A, 8 B$ ). All $(100 \%)$ axonal profiles presynaptic to the A $\delta$ HTM primary afferent boutons, and around $85 \%$ of the axonal profiles presynaptic to peripheral dendrites, contained high densities of gold particles (above four times background levels).

Many dendrites displayed gold densities above background levels, but only a few contained enough gold particles to be clearly classified as GABA immunoreactive (Figs. 7,8 ). The density of gold particles, measured in two or three serial sections of a sample of 56 dendrites receiving a synapse from the A $\delta$ HTM primary afferent, was over four times the background level in 3 dendrites $(5.4 \%)$ and over two times the background level in $16(28.6 \%)$. Both vesicle-containing and non-vesiclecontaining dendrites were in some cases GABA immunoreactive. Similarly, presynaptic dendrites were in some instances immunoreactive but not in others.

Comparison of labeling in dendrites and terminals surrounding the HRP-filled profiles with background yielded statistically significant differences between groups for antibody dilutions from $1: 1000$ to $1: 4000$. ANOVA values were $F=48.91, \mathrm{df}=$ $2,50, p<0.0001$ for a dilution of primary antibody 1:1000 (Fig. $8 A$ ) and $F=93.39$, df $=2,44, p<0.0001$ for a dilution of primary antibody 1:4000 (Fig. 8B). Specifically, Duncan's multiple range test indicated that the terminals were always significantly different from background $(p<0.0001)$, but the population of dendrites did not significantly differ from background $(p<0.4)$. In addition, immunostaining in the terminals using preabsorbed antisera was less than background values and less than immunostaining in terminals with nonpreabsorbed antisera $(t$ tests, $p<0.001)$. This indicates that our background measurements probably included structures specifically recognized by the antibodies and therefore were slightly overestimated (see Materials and Methods). Although the dendrites as a group were not significantly different from background, $t$ test comparisons of background versus two individual dendrites displaying a gold density around two times background level measured in five or more serial sections (see Fig. 8), indicated that

Figure 2. Correlated light and electron microscopy of two fiber segments from the monkey A $\delta$ HTM fiber (PP5\#3) shown in Figure 1. $A$, Light microscopy micrograph from a group of $L I$ varicosities, three $(1-3)$ of which are shown in $B$ in a low-power electron micrograph. $C$, A nonconsecutive serial section of varicosity 2 is shown at higher magnification making a synapse onto a dendrite (arrow); in serial sections this varicosity established six axodendritic synapses. The section shown in $C$ was immunostained with GABA antibodies coupled to $10 \mathrm{~nm}$ gold particles. Two immunolabeled vesicle-containing structures are indicated with asterisks. $D$, Low-power electron micrograph of a cross section through a fiber enlargement and a terminal varicosity shown at light microscopic level in $E$. The arrowheads in $D$ and $E$ point to the same regions of this structure. In serial sections, the terminal varicosity established synaptic contacts with two dendrites $\left(d_{l}, d_{2}\right)$ and was postsynaptic to one vesicle-containing profile. The synapse over $d_{t}$ is marked with an arrow. The fiber enlargement established a total of 13 synapses in serial sections (five of them are indicated with arrows in this cross section). Scale bars: $A, B$, and $E, 10 \mu \mathrm{m} ; C$ and $D, 1 \mu \mathrm{m}$.

Figure 3. Five sections through a lightly HRP-filled terminal from a monkey A $\delta$ HTM fiber (HDM28\#1) (asterisk). This terminal was fully reconstructed from 45 serial sections. The position of each section in the series is indicated by the number in the upper left corner. Sections shown in $A, C, D$, and $E$ were stained with a GABA antiserum, while the section in $B$ was incubated in GABA antiserum preabsorbed with $1 \mu \mathrm{M}$ GABA. The A $\delta$ HTM terminal was surrounded by three vesicle-containing profiles $\left(T_{1}, T_{2}, T_{3}\right)$ that displayed morphological characteristics of axonal terminals in all the serial sections through which we followed them, and were enriched with colloidal gold particles indicative of GABA immunoreactivity $(A, C-E)$. The immunostaining disappeared when the antiserum was preabsorbed with GABA $(B)$. $T$, is presynaptic to the A $\delta \mathrm{HTM}$ terminal (arrows in $A, C) . T_{2}$ is attached to the A $\delta$ HTM terminal by a desmosome (double arrowhead in $A$ ) and is presynaptic to a dendrite of the surrounding neuropil (arrows in $C$ and $D$ ). $T_{3}$ is presynaptic (long arrow in $B$ ) to a dendrite $\left(d_{1}\right)$ contacted also by the A $\delta$ HM terminal. The A $\delta$ HTM terminal was presynaptic to six dendrites, two of which are shown $\left(d_{i}, d_{2}\right.$; synapses are marked with short arrows in $B$ and $\left.E\right)$. Scale bars, $0.5 \mu \mathrm{m}$. 

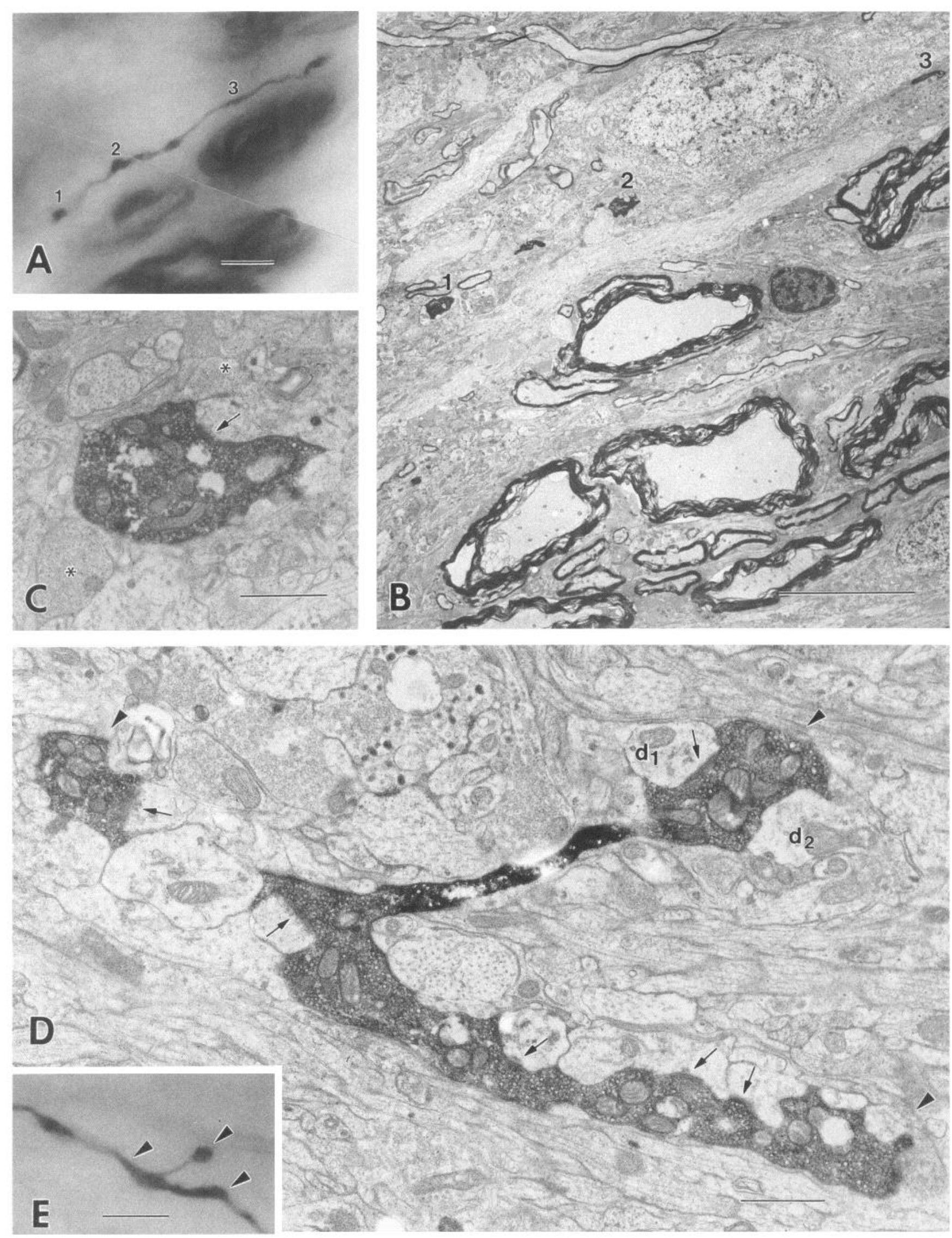

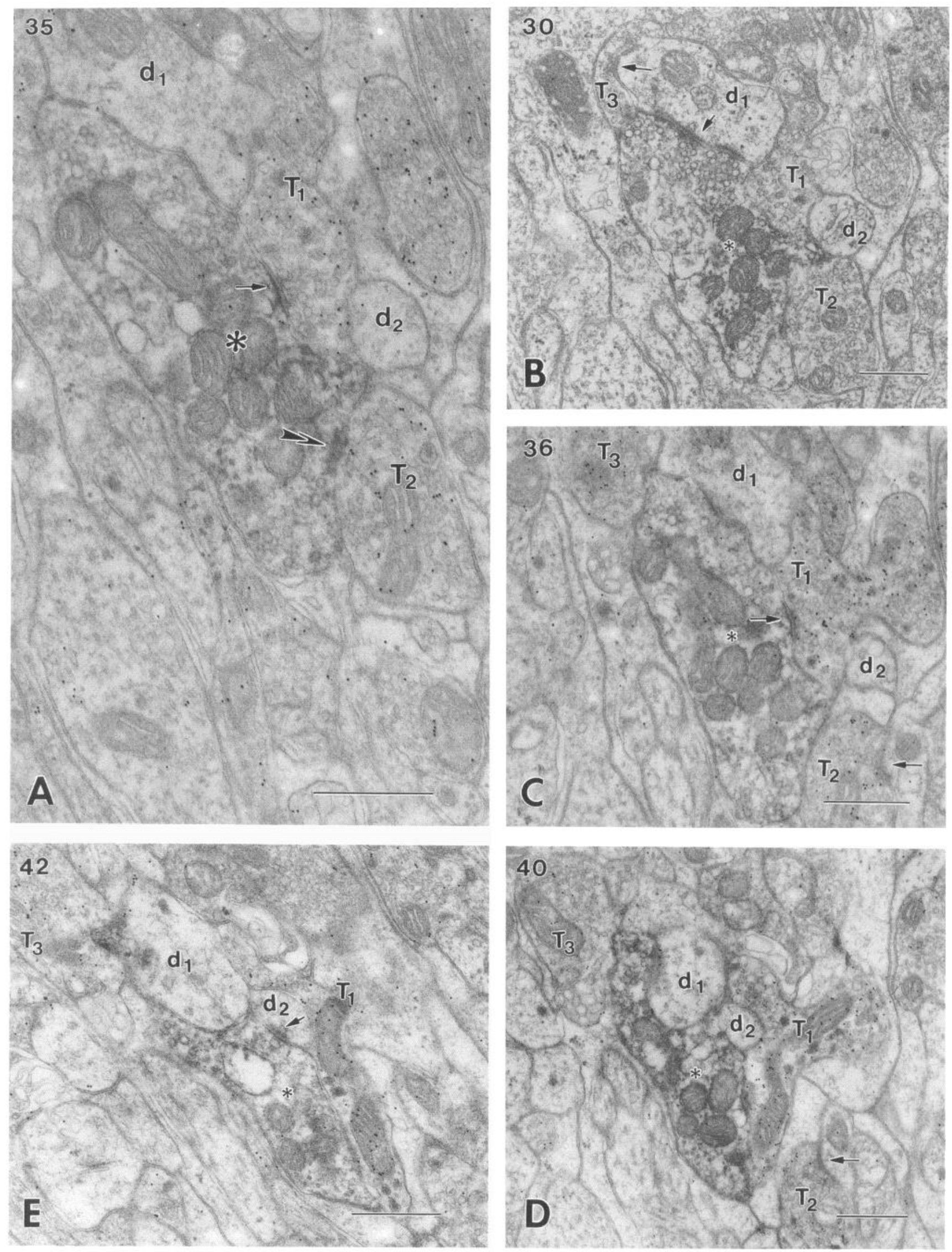

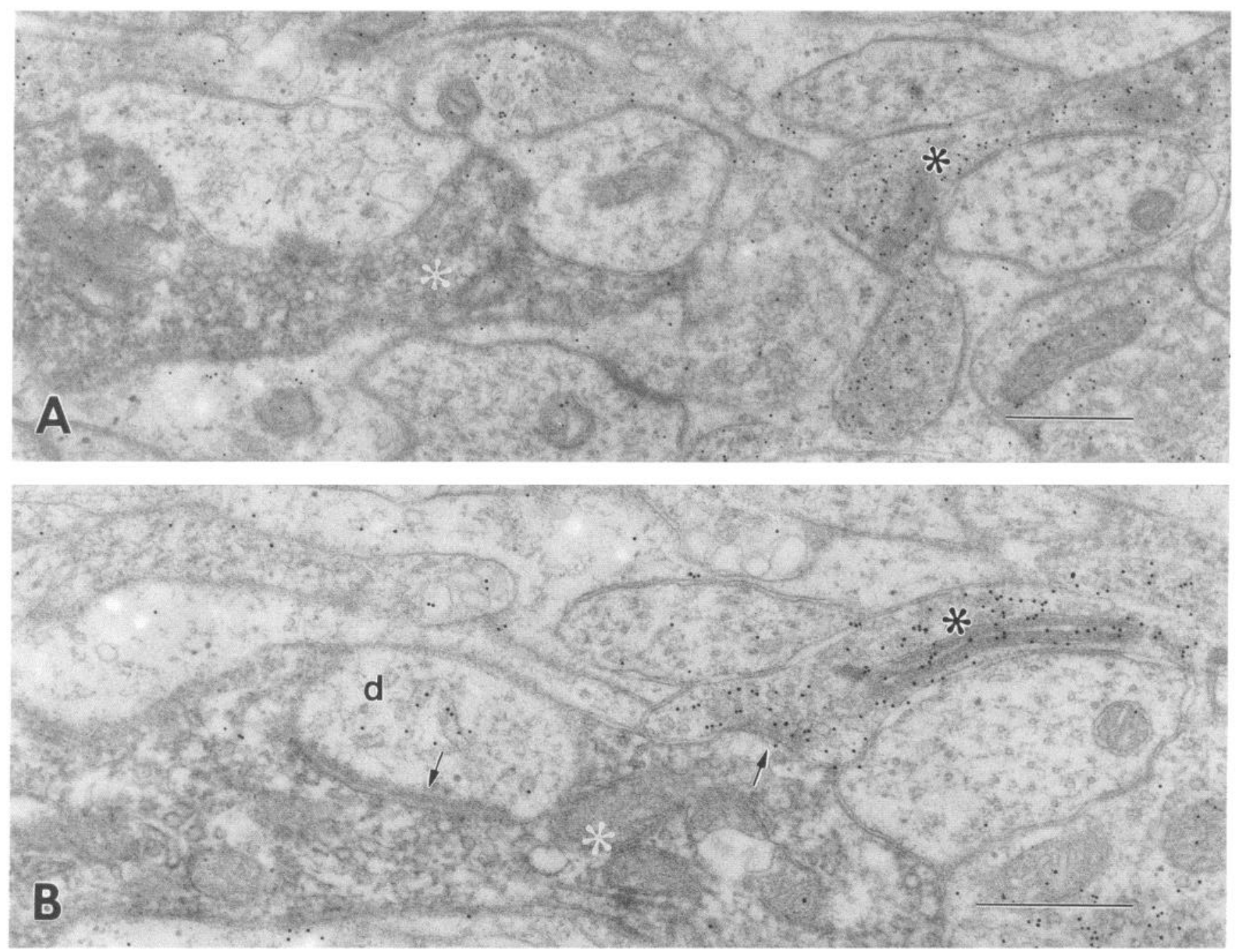

Figure 4. A GABA-immunoreactive terminal (black asterisks) making a presynaptic contact onto a lightly HRP-filled terminal (white asterisks) from a monkey A $\delta$ HTM fiber (HDM28\#1). $A$ and $B$ are two nonconsecutive serial sections showing the varicose appearance of the GABAimmunoreactive fiber. In $B$, the GABA-immunoreactive fiber establishes a symmetric synapse with the A $\delta$ HTM terminal (right arrow). The A $\delta$ HTM terminal establishes an asymmetric synapse (left arrow) with a dendrite (d). Scale bars, $0.5 \mu \mathrm{m}$.

they were significantly labeled $(t$ test, $p<0.01)$. This suggests that structures with gold densities above two times background level are significantly labeled.

\section{Quantitative synaptology of serially reconstructed A $\delta$ HTM boutons}

In order to appreciate the full extent of the complex synaptic interactions inside A $\delta$ HTM glomeruli, we performed a quantitative study in a random sample of terminals that were fully reconstructed in serial sections. Twelve synaptic boutons sampled from fiber HDM28\#1 and 22 from fiber PP5\#3 were completely reconstructed from 15-45 serial sections (Table 2).

Twenty-five of 34 (73\%) A $\delta$ HTM synaptic boutons established synaptic contact with two to six dendrites (modal value $2-4)$. The remaining nine synaptic boutons contacted more than six dendrites (in four cases, 12\%) or a single one (in five cases, $15 \%)$. It has been proposed that a terminal must contact synaptically at least three or four dendrites to be considered as the central terminal of synaptic glomeruli in LI and LII (Ribeiroda-Silva and Coimbra, 1982). Our terminals contacted three or more dendrites in 22 cases $(65 \%)$ and four or more dendrites in 16 cases (47\%). However, many of the HRP-filled terminals in synaptic contact with two dendrites interacted also with peripheral axon terminals in a typical glomerular fashion. Therefore, we considered nonglomerular terminals only those terminals that established a single axodendritic synapse and have no other relation with other elements of the neuropil. Vesiclecontaining dendrites constituted $47 \%$ and $35.4 \%$ of the dendrites postsynaptic to HDM28\#1 and PP5\#3, respectively. The presence of synaptic vesicles in some GABA-immunoreactive dendrites suggests that they may be presynaptic. However, clear dendrodendritic contacts involving a presynaptic and a postsynaptic dendrite both contacted by the same primary afferent synaptic bouton were observed in only two cases after thorough serial section reconstruction of 29 vesicle-containing dendrites. In both cases, the presynaptic dendrites contained some gold particles but positive identification of GABA immunoreactivity remained inconclusive because the gold density was barely above the background level.

Commonly two or three GABA-immunoreactive axonal ter- 

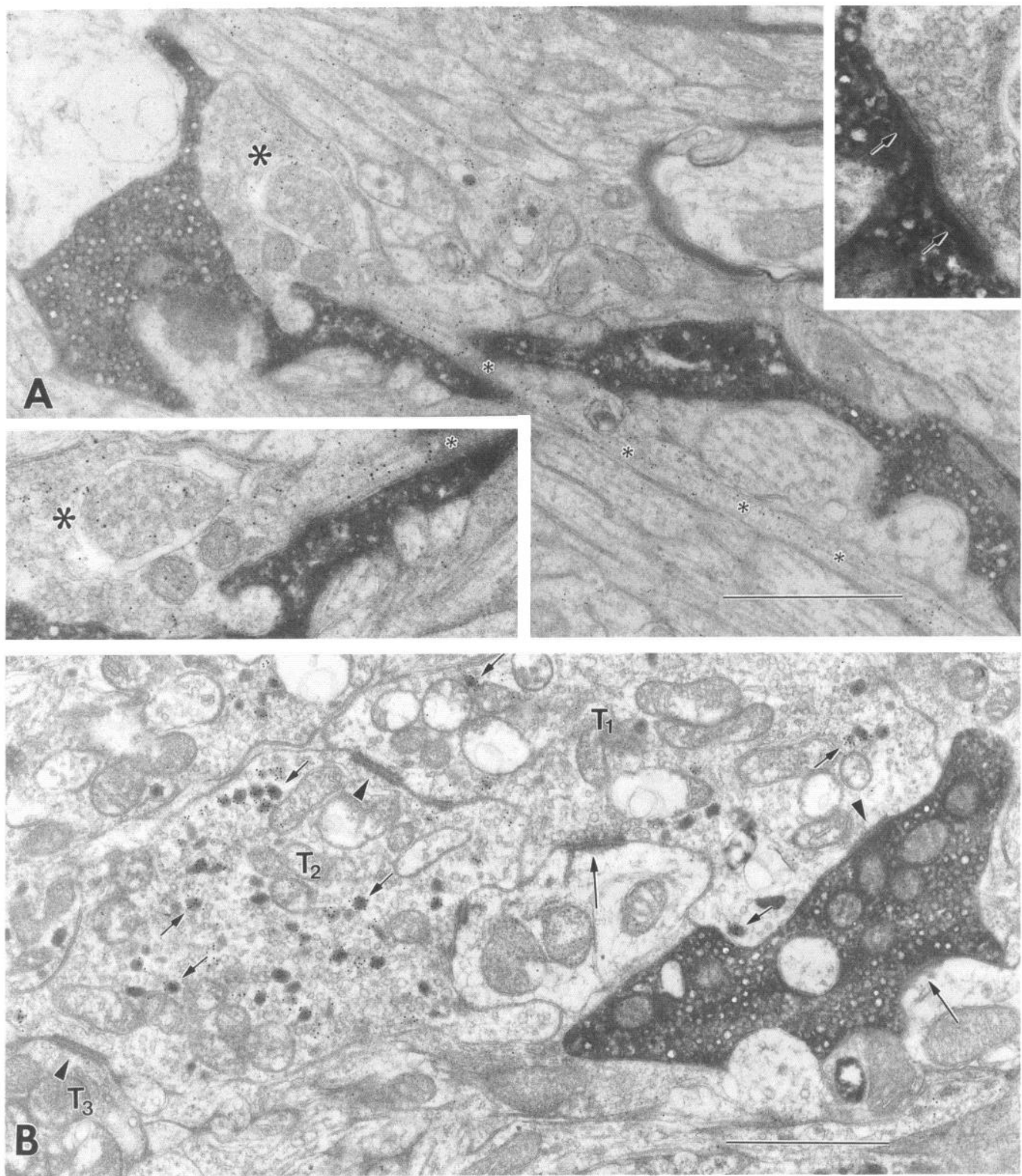

Figure 5. Interactions of two densely HRP-filled terminals from a monkey A $\delta$ HTM fiber (PP5\#3) with other vesicle-containing elements in LII. In $A$, the GABA-immunoreactive terminal (large asterisk; high-power magnification is shown in the left inset) stemming from a long intervaricose segment (small asterisks) is juxtaposed to the A $\delta$ HTM terminal. In a nonimmunostained serial section the GABA-immunoreactive terminal establishes a synapse onto the primary afferent terminal (arrows, right inset). The postsynaptic density is barely visible due to the density of the HRP reaction product; however, most other synaptic characteristics are easily recognized. In $B$, the HRP-filled A $\delta$ HTM terminal is joined by a desmosome (arrowhead) to a series of terminals $\left(T_{1}, T_{2}, T_{3}\right)$ connected also by desmosomes (arrowheads). $T_{1}$ and $T_{2}$ contain large dense-core vesicles (short arrows) in addition to clear round synaptic vesicles. The section was immunostained with SP antiserum, and most large dense-core vesicles in $T_{1}$ and $T_{2}$ display SP immunoreactivity (short arrows). Because of their morphology and SP immunoreactivity, these terminals are most likely derived from primary afferents. The A $\delta$ HTM terminal and $T$, establish synaptic contacts (long arrows) with adjacent dendrites. Scale bars, $1 \mu \mathrm{m}$. 

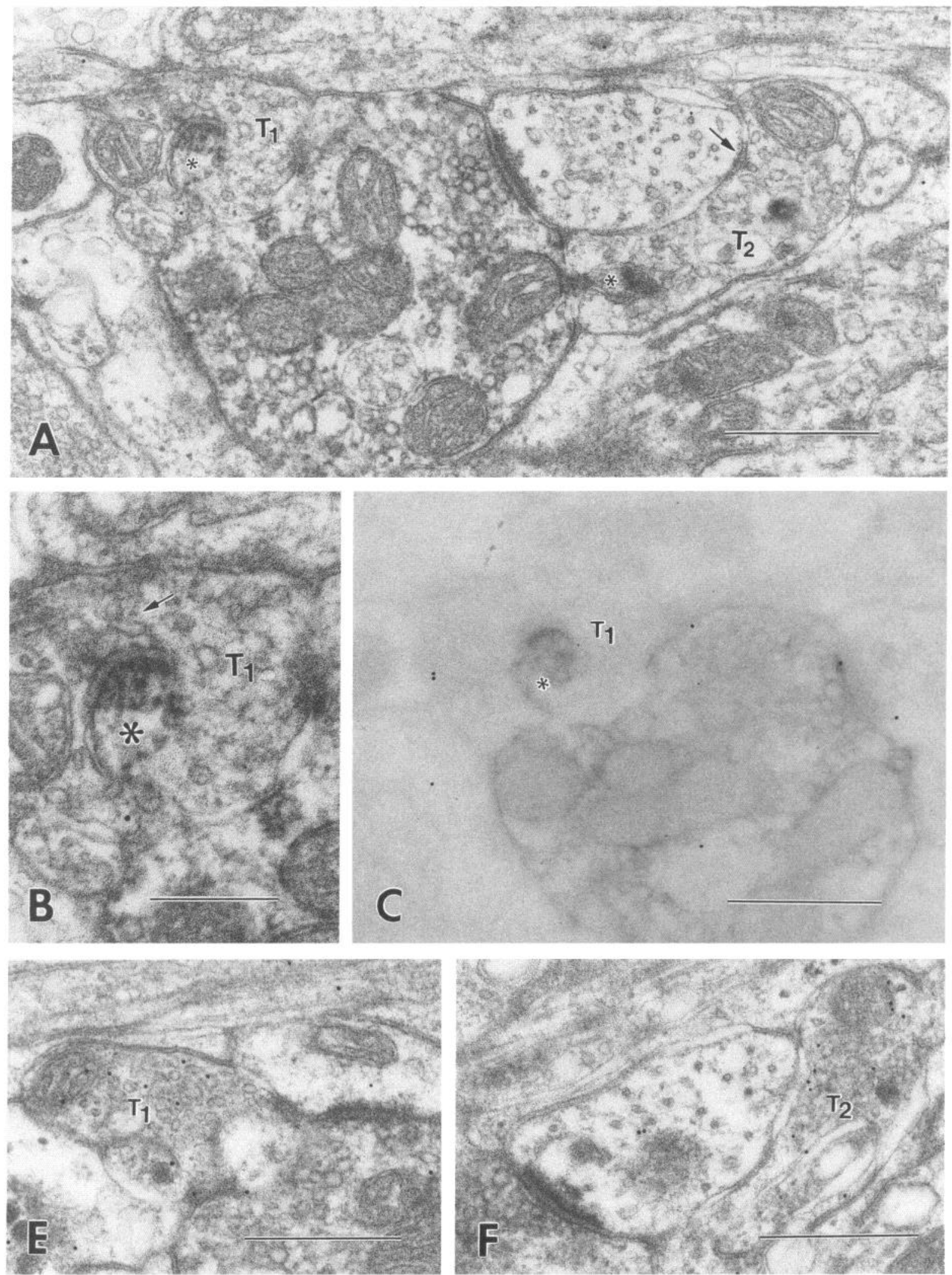

Figure 6. Protruding structures stemming from an A $\delta$ HTM terminal and surrounded by two vesicle-containing profiles. In $A$, two appendages (asterisks) project from a lightly HRP-filled terminal of a monkey A $\delta$ HTM fiber (HDM28\#1). Two vesicle-containing profiles ( $T_{l}, T_{2}$ ) surround the protrusions. $T_{2}$ establishes a synapse (arrow) with a dendrite also postsynaptic to the A $\delta$ HTM terminal. $B$ is a higher magnification of $A$, showing $T$, and the HRP-filled appendage. A vesicle concentration in $T$, (arrow) adjacent to an enlargement and darkening of the extracellular space resembling a synaptic cleft, and a possible postsynaptic density in the spine, all suggest the presence of a synaptic contact from $T_{l}$ onto the HRP-filled appendage. $C$ shows a noncounterstained serial section consecutive to $A$. The lack of contrast renders the HRP reaction product more visible, and therefore the relationship between the little appendage (asterisk) and the HRP-filled varicosity is clearer. $T_{1}$ and $T_{2}$ appear not to be immunolabeled in $A-C$ because these sections were incubated with GABA antiserum preabsorbed with GABA. Both terminals are enriched with gold particles in serial sections $(E, F)$ incubated with nonpreabsorbed GABA antiserum. Scale bars: $A, C, E$, and $F, 0.5 \mu \mathrm{m} ; B, 0.25 \mu \mathrm{m}$. 
minals were apposed to the A $\delta$ HTM terminals. They were presynaptic to the A $\delta$ HTM primary afferent and/or to dendrites in the glomeruli. Due to difficulties in identifying small symmetric synapses onto HRP-labeled profiles, we divided them into "definite" and "possible" axoaxonic synapses. We defined "definite" axoaxonic synapses when all four of the following characteristics were recognized: (1) accumulation of synaptic vesicles in the presynaptic site, (2) presence of dense presynaptic particles, (3) increased extracellular space between pre- and postsynaptic membranes forming a clear synaptic cleft, and (4) presence of postsynaptic densities. "Possible" axoaxonic synapses were defined when at least two typical synaptic features were identified, an accumulation of presynaptic vesicles and any one of the other three structures. Five of $12(41.6 \%)$ and 8 of 12 $(66.7 \%)$ reconstructed synaptic boutons from HDM28\#1 received, respectively, "definite" and "definite + possible" presynaptic input from GABA-immunoreactive axonal terminals. In contrast, 4 of $22(18.2 \%)$ and 7 of $22(32.8 \%)$ reconstructed synaptic boutons from PP5\#3 displayed "definite" and "definite + possible" GABAergic presynaptic contacts from axonal terminals. Dense HRP reaction product can mask postsynaptic densities inside the A $\delta$ HTM fiber and obscure the synaptic clefts. It is therefore not surprising that a larger number of "definite" and "possible" presynaptic contacts werc identified in lightly stained terminals (HDM28\#1) versus heavily labeled terminals (PP5\#3).

\section{Comparison with cat $\mathrm{A} \delta \mathrm{HTM}$ fibers}

One cat A $\delta$ HTM fiber (HD96\#5) was examined as a comparison to the monkey fibers. The ultrastructural characteristics and synaptology of this fiber have been extensively described previously (Réthelyi et al., 1982) and will not be repeated in detail here. Similar to monkey fibers, most "en passant" boutons were surrounded by GABA-immunoreactive axonal terminals that were presynaptic to both A $\delta$ HTM primary afferent synaptic boutons and dendrites (Fig. 9). A $\delta$ HTM primary afferents were presynaptic to vesicle-containing and non-vesicle-containing dendrites that displayed GABA immunoreactivity in some instances. Six boutons were partially reconstructed through semiscrial sections. They cstablished asymmetric synapses with two or three dendrites, $46 \%$ of which were vesicle containing. All six boutons had an axonal terminal apposed to them. The axonal terminal was immunoreactive to GABA in $90 \%$ of the cases. Only one A $\delta$ HTM bouton (17\%) received definite presynaptic input from a GABAergic axonal terminal; however, $46 \%$ of the dendrites were postsynaptic to GABA-immunoreactive axonal terminals. Some GABA-immunoreactive profiles displaying typical dendritic features also contacted dendrites postsynaptic to the HRP-filled A $\delta$ HTM bouton. These data suggest that the synaptology and GABA interactions of cat and monkey A $\delta$ HTM boutons displayed some common features.

\section{Discussion}

The ultrastructural observations presented in this study confirm and extend our previous analysis on the morphology and synaptology of A $\delta$ HTM fibers in the monkey and cat spinal cords (Réthelyi et al., 1982). In addition, we describe GABA immunoreactivity inside various profiles pre- and postsynaptic to $A \delta$ HTM synaptic terminals. The major result of this study is the demonstration of an extensive GABAergic presynaptic control over the synaptic boutons formed by A $\delta$ HTM fibers. Our quantitative estimates indicate that, in a single fiber, between $20 \%$ and $60 \%$ of the A $\delta$ HTM boutons are under presynaptic control by GABA-immunoreactive terminals. In addition, almost all synaptic glomeruli formed by A $\delta$ HTM boutons contained one or more GABA-immunoreactive terminals that converged synaptically onto the same postsynaptic dendritic profiles contacted by the primary afferent terminal. GABA-immunoreactive dendrites were sometimes postsynaptic to A $\delta$ HTM boutons; some of these dendrites containcd synaptic vesicles and may be presynaptic to other dendrites. Therefore, a variety of GABA-containing structures may exert a powerful control, presumably inhibitory, over the transmission through synapses established by nociceptive myelinated primary afferents.

Although we observed some variability in the number of synaptic contacts established by different varicosities along a single A $\delta$ HTM fiber, the majority, after serial section analysis, were found to form the central terminals of synaptic glomeruli. These structures have been described in LI-LIII of several species and are considered to be largely derived from primary afferents (Coimbra et al., 1974; Gobel, 1974; Ralston and Ralston, 1979; Knyihár-Csillik et al., 1982a,b; Snyder, 1982). Of the various types of glomerular terminals described in monkey LII, A $\delta$ HTM glomerular terminals resemble most closely those described by Ralston (1979) as central terminals (C) with either a light or densc axoplasm $(\mathrm{Cl}$ and $\mathrm{Cd}$, respectively). This subtype was later named by Knyihár-Csillik et al. (1982a) the dense sinusoid axon (DSA), a term first introduced by Réthelyi and Szentagothai (1969) for electron-dense terminals that established multiple synapses in the cat LII. In our HRP-filled terminals, axoplasm density is obscured by the DAB precipitate, but the lack of appreciable numbers of large dense-core vesicles and neurofilaments and the high density of round synaptic vesicles packed inside the terminals, their sinusoid contours, and their laminar distribution are defining characteristics of DSA terminals (Knyihár-Csillik et al., 1982a). Monkey and cat A $\delta$ HTM terminals are very similar, as was noted previously for small (Réthelyi et al., 1982) and large myelinated units (Ralston et al., 1984). Therefore, cat A $\delta$ HTM synaptic boutons can also be labeled as DSAs and are similar to the central glomerular terminals described in the cat trigeminal LII (Gobel, 1974). Other laboratories (Ralston and Ralston, 1979; Knyihár-Csillik et al., 1982a) have suggested that $\mathrm{C}$ or DSA terminals stem from unmyelinated axons based on the time course and type of degeneration following rhizotomy. However, our results indicate that small myelinated nociceptive fibers (A $\delta$ HTMs) may also form DSAlike glomerular terminals.

In agreement with our previous report (Réthelyi et al., 1982) and with descriptions of synaptic glomeruli in monkey and cat LII (Gobel, 1974; Ralston, 1979; Knyihár-Csillik et al., 1982a,b), three types of structures surrounded the central A $\delta$ HTM terminal and established synaptic interactions with it: (1) nonvesicle-containing dendrites, (2) vesicle-containing dendrites, and (3) presumed axonal terminals. Strong GABA immunoreactivity was found in the majority of the surrounding axon terminals, and weak GABA immunoreactivity was also detected in some vesicle-containing and non-vesicle-containing dendrites.

GABA-immunoreactive axon terminals were presynaptic to both dendrites and A $\delta$ HTM terminals. Although almost all A $\delta$ HTM synaptic boutons were apposed by at least one GABAimmunoreactive terminal, not all of them received presynaptic input. We estimated that between $20 \%$ and $60 \%$ of the synaptic boutons from single A $\delta$ HTM fibers received presynaptic contact 

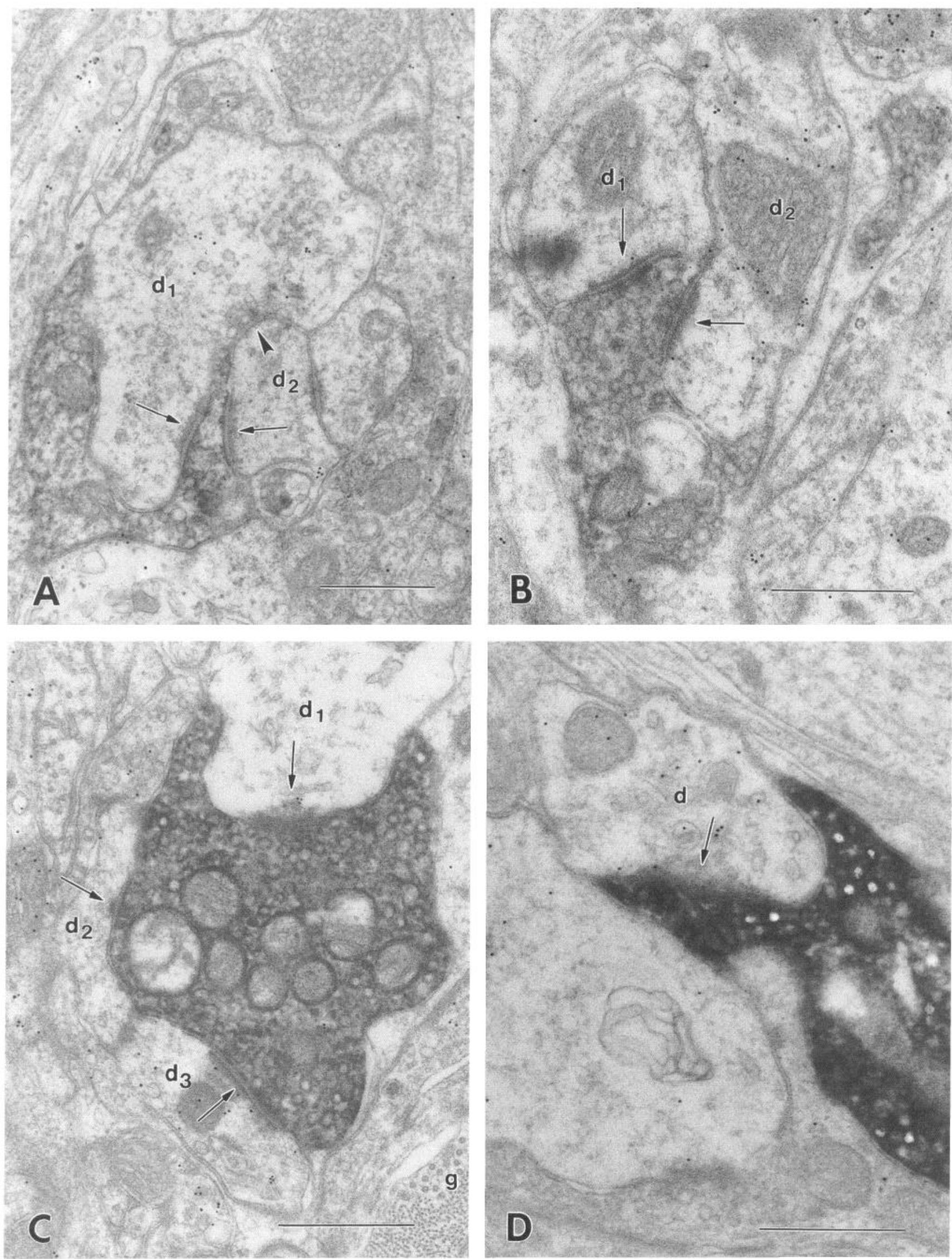

Figure 7. Examples of dendrites receiving a synaptic contact from monkey A $\delta$ HTM terminals. In $A$, a vesicle-containing dendrite $\left(d_{l}\right)$ receives a synapse (arrow) from a lightly HRP-labeled terminal (from HDM28\#1). $d_{1}$ is presynaptic (arrowhead) to a second dendrite $\left(d_{2}\right)$ that is also 

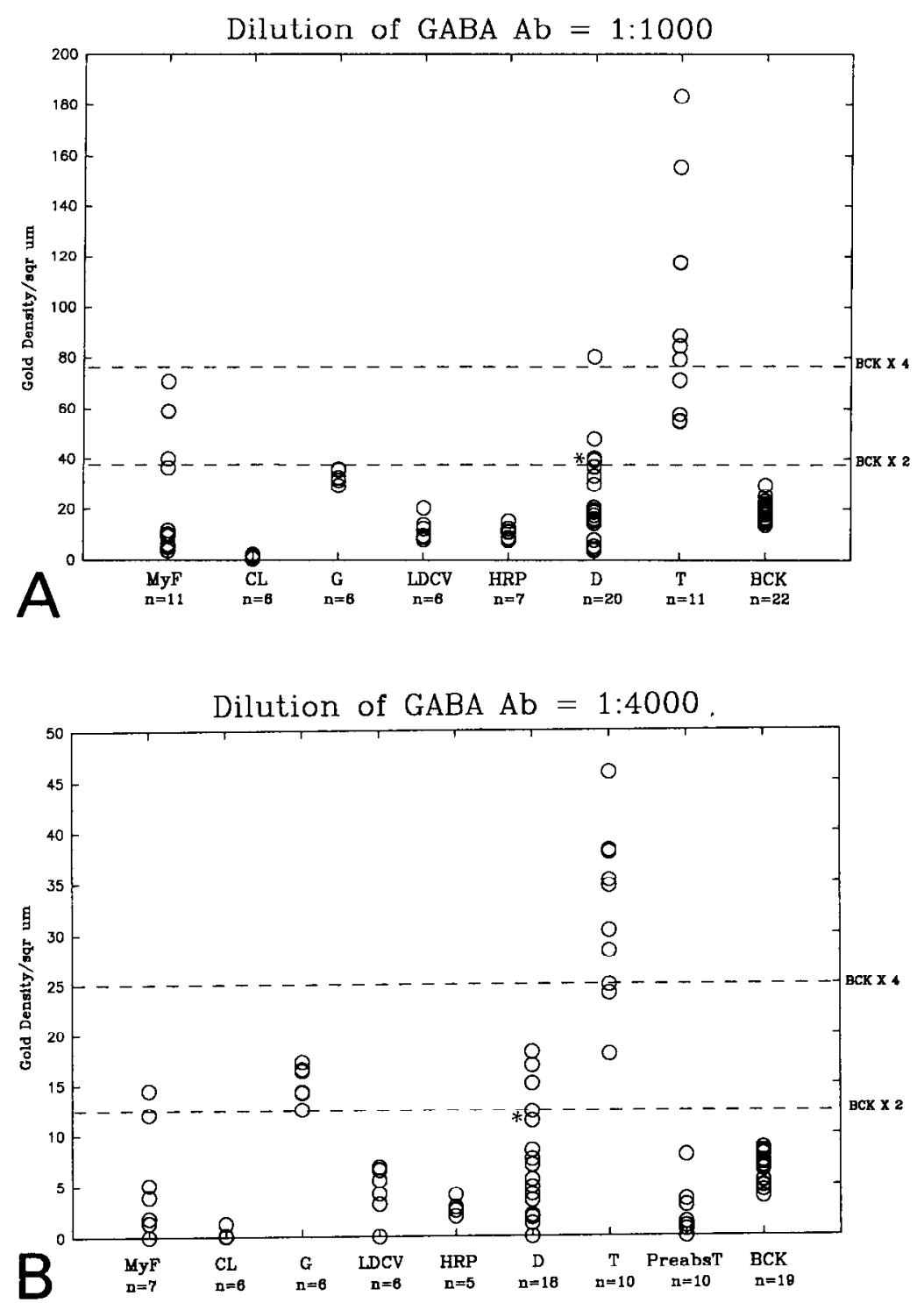

Figure 8. Density plots of two immunocytochemical runs using two different antibody dilutions. Note that although absolute gold density $(y$-axis) is different in both immunoruns, the signal-to-noise ratios are very similar. $M y f$, Myelinated fibers; $C L$, capillary lumen; $G$, oligodendrocytes; $L D C V$, large dense-core vesicle-containing terminals; $H R P$, HRP-labeled A $\delta$ HTM terminal; $D$, dendrites in synaptic contact with the HRP terminal; $T$, terminals apposed to the HRP terminal; PreabsT, the same terminals in serial sections incubated with preabsorbed GABA antibodies; $B C K$, background. Background was $19.6 \pm 3.8$ and $6.4 \pm 1.4$ gold particles $/ \mu \mathrm{m}^{2}$ in $A$ and $B$, respectively. $n$ indicates the number of different individual profiles analyzed. In $A$ and $B$, asterisks indicate two individual dendrites whose gold density, measured through seven and six serial sections, respectively, was compared with background and found to be signifcantly different ( $t$ test, $p<0.01$ ). from GABA-immunoreactive terminals. The disparity between these percentages resulted from applying very strict or more relaxed criteria in the identification of presynaptic synapses onto HRP-filled terminals. Therefore, we believe that these figures are likely to represent the lower and upper limits of the amount of GABA presynaptic input received by A $\delta$ HTM fibers. An average value would be roughly similar to Ralston's (1979) data, which suggested that at least a third of C terminals in LII received presynaptic input. Surprisingly, no presynaptic input was reported by Knyihár-Csillik et al. (1982a,b) over DSA terminals. More strikingly, a recent study in monkeys failed to detect GABAimmunoreactive axon terminals presynaptic to LI-LIII glomerular terminals (Carlton and Hayes, 1990). The fact that we have studied an identified type of primary afferent terminal, while these studies are based on a random sample of the large varicty of glomerular terminals present in LII, may explain the different conclusions reached. Presynaptic control of primary afferent terminals in cat and monkey LI and LII may not be a generalized phenomenon. For example, glomerular terminals containing numerous large dense-core vesicles did not exhibit any presynaptic input (Ralston, 1979; Knyihár-Csillik et al., 1982a,b). Accordingly, immunohistochemical studies provided very few clear examples of presynaptic input over neuropeptidecontaining primary afferent terminals (reviewed in Ruda et al., 1986). We recently confirmed these results in a double-labeling study in which CGRP- and SP-immunoreactive terminals very rarely were postsynaptic to GABA-immunoreactive terminals (Alvarez et al., 1991b). We also showed that at least some pep-

$\leftarrow$

postsynaptic to the HRP-labeled terminal (arrow). This section was incubated with CGRP antiserum. None of the profiles shown in $A$ are immunolabeled. In $B$, a nonimmunoreactive dendrite $\left(d_{1}\right)$ and a GABA-immunoreactive dendrite $\left(d_{2}\right)$ both receive synaptic contacts $(a r r o w s)$ from an HRP-labeled profile (from HDM28\#1). In $C$, a moderately HRP-labeled terminal (from PP5\#3) is presynaptic (arrows) to three different dendrites $\left(d_{1}, d_{2}, d_{3}\right)$. One of them $\left(d_{3}\right)$ contains a few vesicles and is immunolabeled by the GABA antiserum. In $D$, a vesicle-containing dendrite $(d)$ displaying GABA immunoreactivity receives a synaptic contact (arrow) from a very densely HRP-filled terminal (from PP5\#3). Note that the cutting angle prevents the visualization of a synaptic cleft between the dense HRP product and the postsynaptic density. Scale bars, $0.5 \mu \mathrm{m}$. 

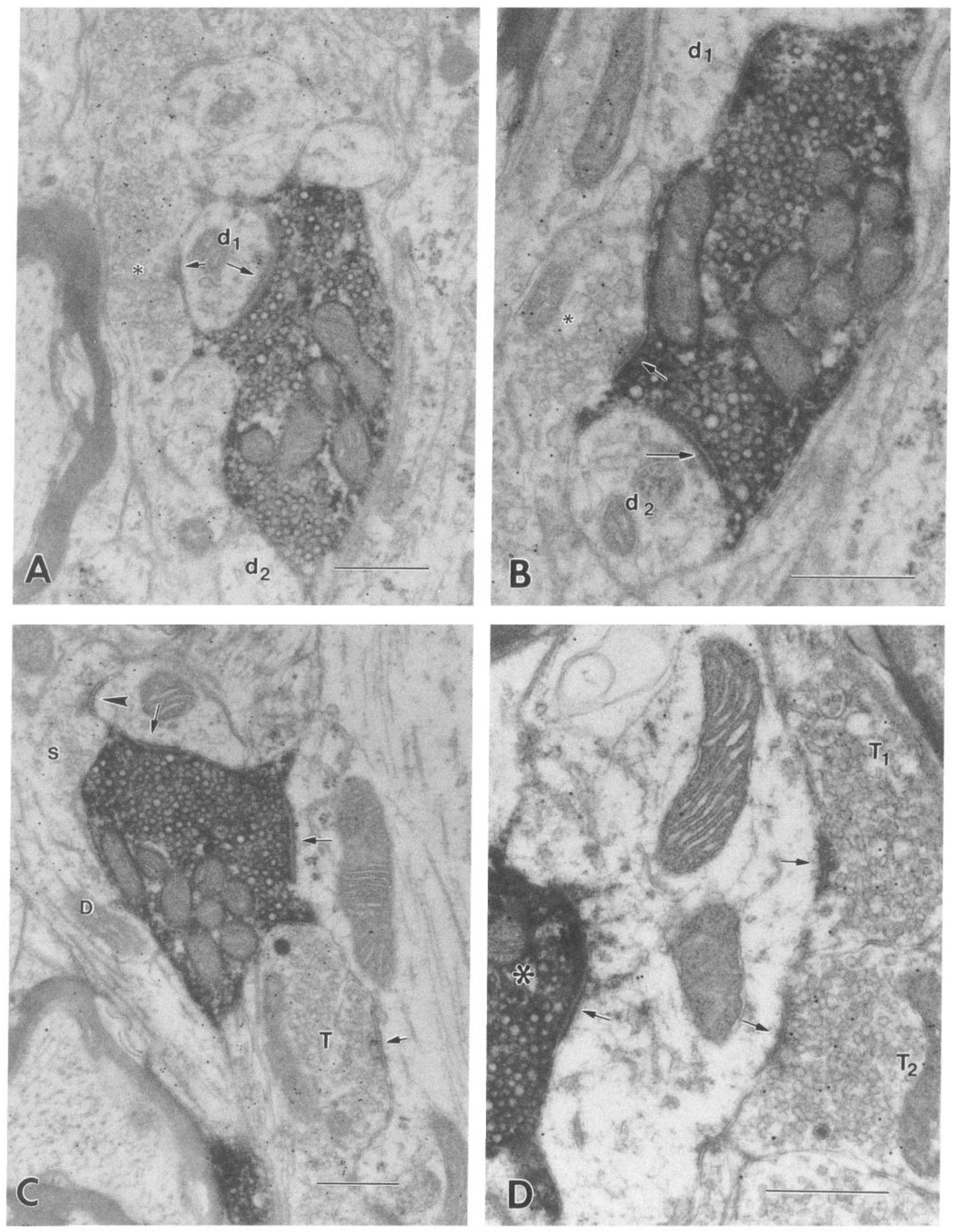

Figure 9. Examples of A $\delta$ HTM terminals from a cat (HD96\#5 fiber) and their relations with adjacent GABA-immunoreactive profiles. In $A$ and $B$, two serial nonconsecutive sections through the same A $\delta$ HTM terminal are shown. The A $\delta$ HTM terminal establishes synaptic contacts (arrows) with two dendritic profiles $\left(d_{1}, d_{2}\right)$. It also receives a presynaptic contact (short arrow in $B$ ) from a GABA-immunoreactive vesicle containing profile 
tidergic terminals belong to intracellularly HRP-filled unmyelinated (C) fibers that did not receive any presynaptic input. Interestingly, GABA has been shown to produce smaller conductance changes in $C$ cell bodies compared to $A$ cell bodies (cell bodies of myelinated axons), suggesting a different GABA receptor density in different types of primary afferent fibers (Désarmenien et al., 1984).

Axon terminals and vesicle-containing dendrites in LII can be very similar morphologically, and extreme caution should be used in the identification of these profiles (for extensive discussions about this problem, see, e.g., Gobel, 1976; Ribeiro-daSilva et al.. 1985; Carlton and Hayes, 1990). Several morphological criteria were proposed to distinguish them from axon terminals, and serial reconstruction analysis was strongly suggested (Gobel, 1974, 1976; Ralston, 1979; Knyihár-Csillik et al. 1982a; Ribeiro-da-Silva and Coimbra, 1982; Ribeiro-daSilva ct al., 1985). Serial section reconstruction may aid in the correct identification of some of these profiles, as when they are found to be connected to a myelinated axon or to large-caliber dendrites. However, in our experience, because of their very fine caliber. most structures peripheral to the A $\delta$ HTM glomerular terminals cannot be followed to larger structures within $15-$ 25 serial sections. In order to be able to classify most peripheral profiles, we have therefore used different criteria. Following detailed ulstrastructural studies by us (Réthelyi et al., 1982) and others (Gobel, 1974, 1976; Ralston, 1979; Knyihár-Csillik et al. 1982a,b: Ribeiro-da-Silva and Coimbra, 1982; Ribeiro-DaSilva et al., 1985), we have assumed that primary afferent central terminals in LI and LII are not presynaptic in axoaxonic synapses or that this synaptic arrangement is exceptionally rare. lherefore, we considered as dendrites those vesicle-containing profiles that received synaptic input from A $\delta$ HTM boutons and considered as axon terminals those vesicle-containing profiles that, after being in apposition to the central terminal through several serial sections, were not postsynaptic to any other profiles. Vesicle-containing profiles classified as dendrites using these criteria were consistently less electron-dense and contained fewer synaptic vesicles than profiles classified as axon terminals. Typical dendritic organelles such as multivesicular bodies, large cisternate from the smooth endoplasmic reticulum, and polyribosome rosettes were observed in some profiles but not in others. Also, unlike axon terminals, GABA immunoreactivity inside vesicle-containing dendrites was always very sparse. This is probably because dendrites contain relatively few synaptic vesicles and the concentration of neurotransmitter is likely to be at the limits of detection for our immunocytochemical technique. Therefore, GABA-containing dendrites only rarely appeared heavily labeled and they may have been underestimated in our present analysis.

Presynaptic dendrites and axon terminals have also been found in rat LII surrounding central glomerular terminals (Ribeiroda-Silva and Coimbra, 1982; Ribciro-da-Silva et al., 1985). They have been conservatively named vesicle-containing profile type
$1\left(V_{1}\right)$ and vesicle-containing profile type $2\left(V_{1}\right)$. respectively In agreement with our results, they have both been shown in some instances to be immunoreactive for glutamic acid decarboxylase (GAD) or GABA antibodies (McLaughlin et al., 1975; Barber et al., 1978; Magoul el al., 1987; Todd and Lochhead, 1990). Recently, Todd and Lochhead (1990) have examined quantitatively the occurrence of GABA-immunoreactive peripheral profiles around type I glomeruli (a glomerular subtypc of rat LII considered homologous to monkey DSA glomeruli: Ribeiro-da-Silva and Coimbra, 1982). Our data agree with theirs in that most peripheral axon terminals $(79 \%)$ were GABA immunoreactive while only $34 \%$ of the vesicle-containing dendrites were immunoreactive to GABA antibodies.

\section{Functional implications}

Our morphological results suggest that GABA-containing terminals modulate the synaptic transmission of nociceptive inputs from A $\delta$ HTM primary afferents to second-order neurons of the monkey and cat spinal cord. This may occur by presynaptic. postsynaptic, or more likely both mechanisms. Unfortunately, direct electrophysiological data about the effects of GABA on A $\delta$ HTM synaptic terminals are difficult to obtaın. However. some parallels may be found with the well-studied primary afferent synapse between Ia primary afferents and motorneurons. GABA-immunoreactive terminals were presynaptic to la terminals and also to the Ia postsynaptic structures (Maxwell e1 al., 1990). Accordingly, both presynaptic and postsynaptic GABA-mediated reductions in the efficiency of synaptic transmission between Ia terminals and motorneurons have been demonstrated (Peng and Frank, 1989a,b). Presynaptic effects on Ia terminals were shown to be mediated by both (jABA, and GABA $_{13}$ receptors (Curtis et al., 1986; Peng and Frank, 1989a.b). Similarly, GABA applied over A $\delta$ cell bodies in the dorsal root ganglion activated a $G A B A_{A}$ receptor (bicuculline sensitive) that depolarized the cell and decreased its input resistance, and a $\mathrm{GABA}_{\mathrm{B}}$ receptor (bicuculline insensitive) that shortened the $\mathrm{Ca}$ component of the action potentials (Désarmenien et al.. 1984). $\mathrm{GABA}_{\mathrm{A}}$ receptors are known to increase a well-studied (1 conductance (Bormann et al., 1987). This may depolarize primary afferent terminals and shunt current, resulting in a reduction of the amplitude of the incoming action potential (Peng and Frank. $1989 \mathrm{a}, \mathrm{b}$ ). [Dorsal root ganglion cells, unlike other neurons, have been shown to concentrate chloride (Gallagher et al., 1978); thus, an increase in chloride conductance causes depolarization.] Activation of $\mathrm{GABA}_{\mathrm{B}}$ receptors in primary afferents has been proposed to block voltage-dependent $\mathrm{Ca}^{2+}$ channels (Dunlap, 1981). and/or to increase $\mathrm{K}^{+}$permeability (Désarmenien et al., 1984), thus reducing the duration of action potentials. Both mechanisms may account for a GABA-mediated decrease in neurotransmitter release from the terminals of $A \delta$ primary afferents. Interestingly, intraspinal application of GABA induced a bicuculline-sensitive decrease in the threshold for antidromic activation of most A $\delta$-fibers, suggesting a partial depolarization

(asterisk in $B$ ). A further GABA-immunoreactive profile (asterisk in $A$ establishes synaptic contact (short arrow) with a dendrite $\left(d_{l}\right)$ also postsynaptic to the A $\delta$ HTM terminal. In (, an A $\delta$ HTM terminal establishes synaptic contacts (arrows) with two dendrites and is surrounded by two GABAimmunoreactive profiles. One GABA-immunoreactive profile displays ultrastructural characteristics of a dendrite $(D)$ and forms a vesicle-filled spine (s) presynaptic (arrowhead) to one of the dendrites postsynaptic to the A $\delta$ HTM terminal. The second GABA-immunoreactive profile was filled with vesicles. displays ultrastructural characteristics of an axon terminal $(T)$, and is presynaptic to one dendrite postsynaptic to the A $\delta$ HTM terminal (short arrow). In $D$, a dendrite receives synaptic contacts (arrows) from an A $\delta$ HTM terminal (asterisk) and two GABA-immunoreactive profiles $\left(T_{1}, T_{1}\right)$. Note that the synaptic vesicles tend to be more flattened in $T_{1}$ than in $T_{2}$. Scale bars, $0.5 \mu \mathrm{m}$. 
of their terminals; however, some A $\delta$-fibers showed bicucullineinsensitive increases in threshold, indicating that in some cases the terminals of these fibers might be hyperpolarized by $\mathrm{GABA}$ (Randic, 1981).

Postsynaptic effects can also be mediated by both types of receptors since $\mathrm{GABA}_{\mathrm{A}}$ and $\mathrm{GABA}_{\mathrm{B}}$ binding sites have been demonstrated in LII (Bowery et al., 1987). Some of these binding sites are probably expressed by LII neurons since at least $50 \%$ of the binding sites for $\mathrm{GABA}_{\mathrm{B}}$ ligands remain after rhizotomy (Price et al., 1987) and LII neurons express the message for various subunits of the $\mathrm{GABA}_{\mathrm{A}}$ receptor (Pershon et al., 1991). Furthermore, excitatory amino acid-evoked activity of nociceptive LI and LII neurons can be suppressed by microiontophoresis of GABA (Jones et al., 1990). These data indicate the existence of GABA synapses on LI and LII dendrites and cell somas as has been well documented in this and other ultrastructural studies (McLaughlin et al., 1975; Basbaum et al., 1986; Magoul et al., 1987; Carlton and Hayes, 1990). In addition, the morphological data suggest that GABA may be released from either axon terminals or vesicle-containing dendrites; in the second case, local potential changes induced by a single or a few synapses may provoke local dendritic release of GABA.

An important issue in understanding the modulation of $\mathrm{A} \delta$ HTM synapses mediated by GABA is the identification of the GABAergic neurons involved and the types of input that control their activity. One possible source of GABA terminals are descending projections from the ventromedial medulla to the spinal cord (Millhorn et al., 1987; Reichling and Basbaum, 1990). However, it is unlikely that these are a major source of LI and LII GABAergic terminals because studies that impaired descending systems (e.g., spinal transection) found no detectable changes in the dorsal horn levels of GABA or GAD (Rizzoli, 1968; Tappaz et al., 1976). In contrast, destruction of dorsal horn interneurons by ischemia correlated with a decreased GABA level (Miyata and Otsuka, 1975). Therefore, the GABA-immunoreactive axon terminals seen in our study are most likely derived from the numerous GABA-immunoreactive cell bodics in LII (Hunt et al., 1981; Barber et al., 1982; Magoul et al., 1987; Carlton and Hayes, 1990). Studies in rat suggest that at least $30 \%$ of LI and LII neurons express GABA immunoreactivity (Todd and Sullivan, 1990). Our results also support the view that LII GABAergic neurons receive monosynaptic input from nociceptive primary afferents, in agreement with previous studies showing synapses from central glomerular terminals onto GABA-immunoreactive dendrites in rat, cat, and monkey LII (Basbaum et al., 1986; Magoul et al., 1987; Carlton and Hayes, 1990). This suggests that A $\delta$ HTM fibers and probably also other types of primary afferents in LII can activate local GABAergic interneurons. In fact, about $30 \%$ of rat LII neurons showed GABA-mediated IPSPs evoked by A $\delta$ primary afferent stimulation (Jessell and Yoshimura, 1990).

According to our results, primary afferent-mediated activation of GABAcrgic neurons could also presynaptically modulate A $\delta$ HTM afferents. Interestingly, noxious stimuli consistently reduced the thresholds of $A \delta$ nociceptive fibers to antidromic stimulation, suggesting a modality specific primary afferentevoked depolarization (PAD) of $\mathrm{A} \delta$ nociceptive fiber terminals in the spinal cord (Whitehorn and Burgess, 1973). GABA-mediated PAD has long been known to occur in the large mechanoreceptive primary afferents, where it may underlie a particular type of lateral inhibition that aids in the discriminatory aspects of low-threshold mechanical sensory processing (for re- view, see Levy 1977; Nicoll and Alger, 1979). Mechanical nociceptors also provide good spatial resolution in spite of receptive fields consisting of separate spots that can cover from 15 $\mathrm{mm}^{2}$ to more than $100 \mathrm{~mm}^{2}$ on the skin (Perl, 1984). This suggests the existence of processing mechanisms for A $\delta$ HTM input comparable to those of low-threshold mechanoreceptive input. However, any inhibitory neuron that can powerfully modulate the transmission of nociceptive input is also a very fitting target for descending systems concerned with pain suppression at the very first synapse. Thus, PAD of A $\delta$ nociceptors could be evoked by stimulating descending systems originating in the caudal medulla (Martin et al., 1979; but see Carstens et al., 1987).

In conclusion, our study provides morphological and immunocytochemical data suggesting that the transmission of nociceptive information from A $\delta$ HTM synaptic boutons is powerfully controlled, both pre- and postsynaptically, by GABAergic neurons. We hypothesize that the activity of these GABAergic neurons is driven by both primary afferents and/or descending systems.

\section{References}

Alvarez FJ, Kavookjian AM, Light AR (1991a) Nociceptive primary afferents are controlled both pre- and postsynaptically by GABAimmunoreactive profiles. Abstract from the Third IBRO World Congress of Neuroscience, Montreal, Quebec, Canada.

Alvarez FJ, Kavookjian AM, Light AR (1991b) Neuropeptide content and interactions with GABA-immunoreactive profiles of physiologically identified lamina I and II monkey primary afferent terminals. Soc Neurosci Abstr 21:1003.

Barber RP, Vaughn JE, Saito K, McLaughlin BJ, Roberts E (1978) GABAcrgic tcrminals are presynaptic to primary afferent terminals in the substantia gelatinosa of the rat spinal cord. Brain Res 141:3555 .

Barber RP, Vaughn JE, Roberts E (1982) The cytoarchitecture of GABAergic neurons in rat spinal cord. Brain Res 238:305-328.

Basbaum AI, Glazer EJ, Oertel W (1986) Immunoreactive glutamic acid decarboxylase in the trigeminal nucleus caudalis of the cat: a light- and electron-microscopic analysis. Somatosens Res 4:77-94.

Bormann J, Hamill OP, Sakmann B (1987) Mechanism of anion permeation through channels gated by glycine and gamma-aminobutyric acid in mouse cultured spinal neurons. J Physiol (Lond) 385:243286.

Bowery NG, Hudson AL, Price GW (1987) $\mathrm{GABA}_{\mathrm{A}}$ and $\mathrm{GABA}_{\mathrm{B}}$ receptor site distribution in the rat central nervous system. Neuroscience 20:365-383.

Carlton SM, Hayes ES (1990) Light microscopic and ultrastructural analysis of GABA-immunoreactive profiles in the monkey spinal cord. J Comp Neurol 300:162-182.

Carstens E, Gilly H, Schreiber H, Zimmermann M (1987) Effects of midbrain stimulation and iontophoretic application of serotonin, noradrenaline, morphine and GABA on electrical thresholds of afferent $\mathrm{C}$ - and A-fibre terminals in cat spinal cord. Neuroscience 21:395406.

Coimbra A, Sodre-Borges BP, Magalhaes MM (1974) The substantia gelatinosa Rolandi of the rat. Fine structure, cytochemistry (acid phosphatase) and changes after dorsal root section. J Ncurocytol 3:199217.

Curtis DR, Gynther BD, Malik R (1986) A pharmacology study of group I muscle afferent terminals and synaptic excitation in lamina VI and Clarke's column of the cat spinal cord. Exp Brain Res 64: 105-113.

Dunlap K (1981) Two types of gamma-aminobutyric acid receptor on embryonic sensory neurones. Br J Pharmacol 74:579-585.

Désarmenien M, Feltz P, Occhipinti G, Santangelo F, Schlichter R (1984) Coexistence of $\mathrm{GABA}_{\mathrm{A}}$ and $\mathrm{GABA}_{\mathrm{B}}$ receptor on $\mathrm{A} \delta$ and $\mathrm{C}$ primary afferents. Br J Pharmacol 81:327-333.

De Zeeuw CI, Holstege JC, Calkoen F, Ruigrok TJH, Voogd J (1988) A new combination of WGA-HRP anterograde tracing and GABA immunocytochemistry applied to afferents of the cat inferior olive at the ultrastructural level. Brain Res 447:369-375. 
Evans RH (1989) The pharmacology of segmental transmission in the spinal cord. Prog Neurobiol 33:255-279.

Gallagher PH, Higashi H, Nishi S (1978) Characterization and ionic basis of GABA-induced depolarizations recorded in vitro from cat primary afferent neurons. J Physiol (Lond) 275:263-282.

Gobel S (1974) Synaptic organization of the substantia gelatinosa glomeruli in the spinal trigeminal nucleus of the adult cat. J Neurocytol 3:219-243.

Gobel S (1976) Dendroaxonic synapses in the substantia gelatinosa glomeruli of the spinal trigeminal nucleus of the cat. J Comp Neurol 167:165-176.

Hepler JR, Petrusz P, Rustioni A (1986) Antisera to GABA, glutamate and aspartate: characterization by immunoabsorption and immunocytochemistry. J Histochem Cytochem 34:110A.

Hunt SP, Kelly JS, Emson PC, Kimmel JR, Miller RJ, Wu JY (1981) An immunohistochemical study of neuronal populations containing neuropeptides or gamma-aminobutyrate within the superficial layers of the rat dorsal horn. Neuroscience 6:1883-1898.

Jessell TM, Yoshimura M (1990) Glycine and GABA-mediated IPSPs in rat substantia gelatinosa evoked by primary afferent stimulation. Soc Neurosci Abstr 16:1182.

Jochem WJ, Light AR, Smith D (1981) A high voltage electrometer for recording and iontophoresis with fine-tipped, high resistance microelectrodes. J Neurosci Methods 3:261-269.

Jones SL, Sedivec MJ, Light AR (1990) Effects of iontophoresed opioids on physiologically characterized laminae I and II dorsal horn neurons in the cat spinal cord. Brain Res 532:160-174.

Knyihár-Csillik E, Csillik B, Rakic P (1982a) Ultrastructure of normal and degenerating glomerular terminals of dorsal root axons in the substantia gelatinosa of the rhesus monkey. J Comp Neurol 210:357375.

Knyihár-Csillik E, Csillik B, Rakic P (1982b) Periterminal synaptology of dorsal root glomerular terminals in the substantia gelatinosa of the spinal cord of the rhesus monkey. J Comp Neurol 210:376 -399.

Levy RA (1977) The role of GABA in primary afterent depolarization. Prog Neurobiol 9:211-267.

Light AR. Perl ER (1979) Spinal termination of functionally identified primary afferent neurons with slowly conducting myelinated fibers. $J$ Comp Neurol 186:133-150.

Magoul R, Onteniente B, Geffard M, Calas A (1987) Anatomical distribution and ultrastructural organization of the GABAergic system in the rat spinal cord. An immunocytochemical study using antiGABA antibodies. Neuroscience 20:1001-1009.

Martin RF, Haber LH, Willis WD (1979) Primary afferent depolarization of identified cutaneous fibers following stimulation in medial brain stem. J Neurophysiol 42:779-790.

Maxwell DJ, Christie WM, Short AD, Brown AG (1990) Direct observations of synapses between GABA-immunoreactive boutons and muscle afferent terminals in lamina VI of cat's spinal cord. Brain Res 530:215-222.

McLaughlin BJ, Barber R, Saito K, Roberts E, Wu JY (1975) Immunocytochemical localization of glutamate decarboxylase in rat spinal cord. J Comp Neurol 164:305-322.

Merighi A, Polak JM, Theodosis DJ (1991) Ultrastructural visualization of glutamate and aspartate immunoreactivities in the rat dorsal horn, with special reference to the co-localization of glutamate, substance $P$ and calcitonin genc-related peptide. Neuroscience 40:67-80.

Metz CB, Kavookjian AM, Light AR (1982) Techniques for HRP intracellular staining of neural elements for light and electron microscopic analyses. J Electrophysiol Tech 9:151-163.

Millhorn DE, Hökfelt T, Seroogy K, Oertel W, Verhofstad AAJ, Wu $\mathrm{J}-\mathrm{Y}$ (1987) Immunohistochemical evidence for colocalization of gamma-aminobutyric acid and serotonin in neurons of the ventral medulla oblongata projecting to the spinal cord. Brain Res 410:179185.

Miyata Y, Otsuka M (1975) Quantitative histochemistry of gammaaminobutyric acid in cat spinal cord with special reference to presynaptic inhibition. J Neurochem 25:239-244.

Nicoll RA, Alger BE (1979) Presynaptic inhibition: transmitter and ionic mechanisms. Int Rev Neurobiol 21:217-258.

Peng YY, Frank E (1989a) Activation of GABA F $_{\mathrm{B}}$ receptors causcs presynaptic inhibition at synapses between muscle spindle afferents and motorneurons in the spinal cord of bullfrogs. J Neurosci 9:15021515.

Peng YY, Frank E (1989b) Activation of $\mathrm{GABA}_{\mathrm{A}}$ receptors causes presynaptic and postsynaptic inhibition at synapses between muscle spindle afferents and motor neurons in the spinal cord of bullfrogs. $J$ Neurosci 9:1516-1522.

Perl ER (1984) Pain and nociception. In: Handbook of physiology, Vol 3, The nervous system (Darian-Smith I, ed), pp 915-975. Bethesda, MD: American Physiological Society.

Pershon E, Malherbe P, Richards JG (1991) In situ hybridization histochemistry reveals a diversity of GABAA receptor subunit mRNAs in neurons of the rat spinal cord and dorsal root ganglia. Neuroscience 42:497-507.

Phend KD, Weinberg RJ, Rustioni A (1992) Techniques to optimize post-embedding single and double staining for amino acid neurotransmitters. J Histochem Cytochem, in press.

Price GW, Kelly JS, Bowery NG (1987) The localization of GABA receptor binding sites in mammalian spinal cord. Synapse 1:530-538.

Ralston HJ (1979) The fine structure of laminae I, II and III of the macaque spinal cord. J Comp Neurol 184:619-641.

Ralston HJ, Ralston DD (1979) The distribution of dorsal root axons in laminae I, II and III of the macaque spinal cord: a quantitative electron microscope study. J Comp Neurol 184:643-683.

Ralston HJ, Light AR, Perl ER, Ralston DD (1984) Morphology and synaptic relationships of physiologically identified low threshold dorsal root axons stained with intraaxonal horseradish peroxidase in the cat and monkey. J Neurophysiol 51:777-792.

Randic M (1981) Presynaptic effects of gamma-aminobutyric acid and substance $P$ on intraspinal single cutaneous $C$ - and A-fibres. In: Spinal cord sensation (Brown AG, Réthelyi M, eds), pp 285-294. Edinburgh: Scottish Academic.

Reichling DB, Basbaum AI (1990) Contribution of brainstem GABAergic circuitry to descending antinociceptive controls: I. GABAimmunoreactive projecting neurons in the periaqueductal gray and nucleus raphe magnus. J Comp Neurol 302:370-377.

Réthelyi M, Szentagothai J (1969) The large synaptic complexes of the substantia gelatinosa. Exp Brain Res 7:258-274.

Réthelyi M, Light AR, Perl ER (1982) Synaptic complexes formed by functionally defined primary afferent units with fine myelinated fibers. J Comp Neurol 207:381-393

Ribeiro-da-Silva A, Coimbra A (1982) Two types of synaptic glomeruli and their distribution in laminae I-III of the rat spinal cord J Comp Neurol 209:176-186.

Ribeiro-da-Silva A, Cuello AC (1990) Choline acetyltransferase-immunoreactive profiles are presynaptic to primary sensory fibers in the rat superficial dorsal horn. J Comp Neurol 295:370-384.

Ribeiro-da-Silva A, Pignatelli D, Coimbra A (1985) Synaptic architecture of glomeruli in superficial dorsal horn of rat spinal cord, as shown in serial reconstructions. J Neurocytol 14:203-220.

Rizzoli AA (1968) Distribution of glutamic acid, aspartic acid, gamma-aminobutyric acid and glycine in six areas of cat spinal cord before and after transection. Brain Res 11:11-18.

Ruda MA, Bennett GJ, Dubner R (1986) Neurochemistry and neural circuitry in the dorsal horn. Prog Brain Res 66:219-268.

Sawynok J, Sweeney MI (1989) The role of purines in nociception. Neuroscience 32:557-569.

Snyder RL (1982) Light and electron microscopic autoradiographic study of the dorsal root projections to the cat dorsal horn. Neuroscience 7:1417-1437.

Tappaz ML, Zivin JA, Kopin IJ (1976) Intraspinal glutamic decarboxylase after transection of the cord at the thoracic level. Brain Res 111:220-223.

Todd AJ (1990) An electron microscope study of glycine-like immunoreactivity in laminae I-III of the spinal dorsal horn of the rat. Neuroscience 39:387-394.

Todd AJ, Lochhead V (1990) GABA-like immunoreactivity in type I glomeruli of rat substantia gelatinosa. Brain Res 514:171-174.

Todd AJ, Sullivan AC (1990) Light microscope study of the coexistence of GABA-like and glycine-like immunoreactivities in the spinal cord of the rat. J Comp Neurol 296:496-505.

Whitehorn D, Burgess PR (1973) Changes in polarization of central branches of myelinated mechanoreceptor and nociceptor fibers during noxious and innocuous stimulation of the skin. J Neurophysiol 36: 226-237.

Yaksh TL (1986) The central pharmacology of primary afferents with emphasis on the disposition and role of primary afferent substance P. In: Spinal afferent processing (Yaksh TL, ed), pp 165-195. New York: Plenum. 